\title{
Elastoplastic deformation and damage process in duplex stainless steels studied using synchrotron and neutron diffractions in comparison with a self-consistent model
}

\author{
A. Baczmański ${ }^{\text {a, }}{ }^{*}$, Y. Zhao $^{\text {b }}$, E. Gadalińska ${ }^{c}$, L. Le Joncour ${ }^{\text {b }}$, S. Wroński ${ }^{\text {a }}$, \\ C. Braham ${ }^{\mathrm{d}}$, B. Panicaud ${ }^{\text {b }}$, M. François ${ }^{\text {b }}$, T. Buslaps ${ }^{\text {e }}$, K. Soloducha ${ }^{\text {a }}$ \\ a AGH- University of Science and Technology, WFiIS, al. Mickiewicza 30, 30-059 Krakow, Poland \\ ${ }^{\mathrm{b}}$ ICD-LASMIS, Université de Technologie de Troyes (UTT), UMR CNRS 6281, 12 rue Marie Curie, CS 42060, 10004 Troyes, France \\ ${ }^{\mathrm{c}}$ Institute of Aviation, al. Krakowska 110/114, 02-256 Warszawa, Poland \\ d PIMM, Arts et Métiers ParisTech (ENSAM), UMR CNRS 8006, 151 Bd de l'Hôpital, 75013 Paris, France \\ e ESRF, 6, rue J. Horowitz, 38500 Grenoble Cedex, France
}

\section{A R T I C L E I N F O}

\section{Article history:}

Received 26 November 2015

Received in revised form 23 January 2016

Available online 6 February 2016

Keywords:

B. Polycrystalline material

A. Yield condition

A. Fracture mechanisms

C. Numerical algorithms

Diffraction measurements

\begin{abstract}
A B S T R A C T
In situ time of flight neutron diffraction and X-ray synchrotron diffraction methods were applied to measure lattice strains in duplex steels during a tensile test. The experimental results were used to study slips on crystallographic planes and the mechanical effects of damage occurring during plastic deformation. For this purpose the prediction of an elastoplastic self-consistent model was compared with the experimental data. The used methodology allowed to determine the elastic limits and parameters describing work hardening in both phases of studied polycrystalline materials.

In the second part of this work the developed elastoplastic model was applied to study damage occurring in the ferritic phase. The theoretical results showed a significant reduction of stresses localized in the damaged phase (ferrite) and confirmed the evolution of the lattice strains measured in the ferritic and austenitic phases.
\end{abstract}

\section{Introduction}

Duplex stainless steels are two-phase materials composed of an alpha phase (ferrite) having a b.c.c. crystal structure and a gamma phase (austenite) exhibiting an f.c.c. structure. Both phases combine high corrosion resistance and high mechanical properties, i.e. the ferrite increases the value of yield stress, and the austenite provides a ductile behavior. Several studies of a cast duplex steel used in nuclear power plants have been published (Bugat et al., 2001; M'Cirdi et al., 2001). These steels are subjected to a slow thermal aging at the working temperature of $320^{\circ} \mathrm{C}$, which causes an embrittlement of the ferritic phase (Bonnet et al., 1990). As shown in the literature, the spinodal decomposition of ferrite into $\alpha$ (poor in $\mathrm{Cr}$ ) and $\alpha^{\prime}$ (rich in Cr) phases and the precipitation of G-phase (rich in Ni, Mo and Si) occur at temperatures lower than $475{ }^{\circ} \mathrm{C}$ (Park and Kwon, 2002). The presence of $\alpha^{\prime}$ and $G$ phases reduces mobility of dislocations and consequently cause hardening and embrittlement of the ferrite (Lagneborg, 1967). The G particles are very small (between 1 and $10 \mathrm{~nm}$, and up to maximum $50 \mathrm{~nm}$ ) and

\footnotetext{
* Corresponding author.

E-mail address: Andrzej.Baczmanski@fis.agh.edu.pl (A. Baczmański).
} 
they are usually homogenously distributed in the ferritic grains. The largest particles are formed in defects as well as in the interfaces $\left(\alpha / \alpha^{\prime}\right.$ and austenite/ferrite).

It is known that the plastic strains in this material are homogeneous in the austenitic phase and more localized in the ferritic phase, where less slips but with a higher magnitude are observed (El Bartali et al., 2010; Bugat et al., 2001). As SEM (Scanning Electron Microscopy) examinations for cyclic loadings has shown, the slip systems are first activated in the austenite, before slips in the ferrite (El Bartali et al., 2010). Due to the above described mechanisms, the damage in aged duplex stainless steel appears mainly in the ferrite. For instance, cleavage micro-cracks oriented perpendicularly to the direction of loading were shown by M'Cirdi et al. (2001) and Bugat et al. (2001). Moreover, M'Cirdi et al. (2001) used X-ray diffraction during an in situ tensile test to determine lattice strains and stress evolution in coarse-grained ferrite within a cast aged duplex steel. As a result, a significant decrease of the stress/strain perpendicular to $\{100\}$ crystallographic planes was observed for this ferritic grain in which cleavage cracks appeared. Using electron microscopy (EBSD, TEM and SEM techniques) the initiation of cracks due to a cyclic loading was also seen in the ferritic phase (Balbi et al., 2009; El Bartali et al., 2008; Strubbia et al., 2014, Alvarez-Armas et al., 2012; Krupp et al., 2015). Recently, the electron microscopy studies were correlated with X-ray synchrotron diffraction and the effect of significant lattice strain release in damaged ferrite grains was confirmed by Istomin et al. (2014).

Most of the experimental works concerning damage in polycrystalline materials were based on a direct observation of cracks initiation and evolution using electron microscopy (e.g. Strubbia et al., 2014; Istomin et al., 2014; Krupp et al., 2015) or X-ray tomography (e.g. Maire et al., 2005; Bettaieb et al., 2011; Krupp et al., 2015). In the present work, an elastoplastic behavior of grains, as well as initiation of micro-damage during monotonic loading of a two-phase material (duplex steel) will be studied by diffraction methods and the experimental results will be interpreted using a multiscale elastoplastic model. Using diffraction the measurements of lattice strains can be performed selectively for the groups of crystallites contributing to the intensity of the scattered beam. In the case of multiphase materials the strains can be measured independently for each phase if the diffraction peaks are well separated (Inal et al., 1999; Daymond and Priesmeyer, 2002; Fréour et al., 2003; Baczmański and Braham, 2004; Dakhlaoui et al., 2006; Jia et al., 2009; Baczmański et al., 2011; Gloaguen et al., 2013; Francis et al., 2014). Although it is selective, diffraction enables sampling of a significant volume of the material (several hundred or many more crystallites for one peak and almost the whole irradiated volume when several scattering vector orientations are analyzed) and thus leads to statistically significant results.

The diffraction measurements performed in situ during tensile tests were usually compared with the Eshelby (1957) type models using a small deformation formalism (up to ca. $10 \%$ of sample strain). For instance, the self-consistent model developed for anisotropic polycrystals by Turner and Tomé (1994), was used for the interpretation of the diffraction measurements by Clausen et al. (1999), Daymond and Priesmeyer (2002), Francis et al. (2014) and Jia et al. (2008, 2009). This method was also applied by Neil et al. (2010) to study mechanical phenomena occurring at microscale in the polycrystalline copper and austenitic steel deformed up to $c a$. $30 \%$ of sample strain. In that work the rotations of the grain lattice was used to predict evolution of texture during plastic deformation and the model values of lattice elastic strains were successfully compared with diffraction results.

Another self-consistent elastoplastic model but also based on the Eshelby-type interaction was elaborated by Lipinski and Berveiller (1989). In the frame of this model the calculations can be done for arbitrary large strains and the rotation of the grain lattice is considered. More recently, this scale transition model was applied to study the influence of intragranular microstructure on ductility and forming limits in multiphase steels or single phase b.c.c. steel (Franz et al., 2014), and analysis of stress localization for polycrystalline material (Franz et al., 2013). The same model was also used for the interpretation of diffraction measurements performed for two-phase duplex steels (Baczmański and Braham, 2004; Baczmański et al., 2011; Wroński et al., 2007).

In the frame of Finite Element Analysis (FEA) the modeling of damage can be carried out in two ways. The first one is to introduce discrete elements corresponding to cracks or voids. The dynamic evolution of these discontinuities enables description of the different stages of damage evolution: germination, growth and coalescence. Such a description is adapted to ductile materials through a scalar variable describing the volume fraction evolution of those cracks or voids. Over the years several modified models have been proposed, taking anisotropy effects into account (Li et al., 2011; Bettaieb et al., 2011; Lecarme et al., 2011; Malcher et al., 2014, among others).

In the second approach, a continuum thermodynamics methodology is applied to obtain the so-called Continuum Damage Mechanics (CDM). In the CDM method the dissipation potentials and variables describing damage are derived in the frame of the thermodynamics. In this formulation damage is one of the internal constitutive variables describing the irreversible processes occurring in the material. The local CDM theory developed by Lemaitre and Chaboche (1978) assumed that the strain tensor and the damage parameter are defined at a given point of the continuum. To avoid strain localization at vanishing volume, the non-local continuum approach based on the concept of Representative Volume Element (RVE) was proposed (Pijaudier-Cabot and Bažant, 1987). The non-local damage models consist in replacing a certain variable by a mean value averaged over a spatial neighborhood of each considered point. Several modified models have been proposed in more recent years accounting for different effects in the frame non-local modeling (Marotti De Sciarra, 2012; Basirat et al., 2012; Brünig et al., 2015; Vignjevic et al., 2012; Balieu and Kringos, 2015; Nguyen et al., 2015; Dormieux and Kondo, 2015, among others).

The damage effect was also included into continuum models introducing additional information from the microscopic level of complex materials. The direct multiscale FEA calculations of the real microstructures are computationally expensive, 
therefore the micromechanical mean field approaches were embedded into FEA in order to model the damage occurring at a microscopic scale of multiphase polycrystalline materials, composites and polymers. Such formulations can combine the features of continuum models and physical models, enabling the introduction of crystal plasticity and elasticity in calculations.

For example, Gonzàlez and LLorca (2000) and Gonzàlez et al. (2004) introduced damage into a mean-field self-consistent model based on the Eshelby (1957) solution for ellipsoidal inclusion in order to calculate the effective mechanical properties of the particle reinforced $\mathrm{Al} / \mathrm{SiC}$ Metal Matrix Composite (MMC). Using the volume fraction of damaged SiC particles (reinforcement) as a damage variable, the effect of elastic constants reduction leading to an elastic stress relaxation was predicted in accordance with the experimental mechanical stress-strain test. Another model accounting for fracture of the ceramic reinforcement in MMC was proposed and developed by Tekoğlu and Pardoen (2010). In this approach the void nucleation, growth and coalescence were taken into account in the frame of the Mori and Tanaka (1973) homogenization scheme applied for the RVE containing reinforcement particles. Ran and Fu (2014) constructed and tested on a brass C3602 sample the socalled 'hybrid flow stress model' for multiphase polycrystalline materials. This model, included in an FEA, allows determining of the contribution of each phase to the mechanical properties of materials and uses fracture energy to predict the ductile fracture.

The Eshelby-based approach was also used in the Transformation Field Analysis (TFA), developed by Chaboche et al. (2001) and Michel and Suquet (2003), consisting in decomposing the RVE in a number of sub-phases. The macroscopic constitutive equations and stress/strain localization tensors for each phase can be built up from multi-scale approach, for instance using the self-consistent or Mori-Tanaka models (e.g. Chaboche et al., 2001; Shojaei and Li, 2013). The TFA approach were applied for MMC and elasto-viscoplastic polymers, including the crystal elasticity in calculations, crystal plasticity as well as viscoplastic behavior of amorphouse phase (Shojaei and Li, 2013). Moreover, the multi-scale analysis in the frame of TFA was coupled with damage (Chaboche et al., 2001; Kruch and Chaboche, 2011).

An interesting attempt to include anisotropic damage to an elastic-viscoplastic model was made by Ekh et al. (2004). It was shown that the softening/hardening behavior of the crystal viscoplasticity model is strongly affected by the damage. However, the proposed model was applied to predict damage of a crystallite but the calculations were not developed for polycrystalline materials.

Another micromechanical damage model working in the frame of FEA was proposed by Boudifa et al. (2009). In the constitutive equations used in the calculations, the ductile damage was coupled with deformation of the f.c.c. polycrystals by introducing the ductile damage variable at the level of crystallographic slip systems. This formulation enabled to describe influence of the microdefects on the degradation of polycrystalline grains and may reveal information about grains deformation heterogeneity, as well as about texture and residual stresses evolution. The model proposed by Boudifa et al. (2009) is based on physical phenomena occurring at microscopic scales and it is suitable for predicting damage processes in aged duplex steels, where ductile fracture first takes place along slip systems and is not related to cracks or voids at the larger grain and/or macroscopic scales. The limitations of this method are: a small number of grains for which the calculations can be performed (24 grains), isotropic elasticity introduced for crystallites and a simplified scale transition rule in which the grains interaction is described by scalar phenomenological function (postulated by Cailletaud and Pilvin, 1994). The work of Boudifa et al. (2009) was an inspiration for the present work in which an Eshelby-type self-consistent approach was used to avoid the described above limitations. Originally, the model upgraded and modified in this work was proposed in the paper by Panicaud et al. (2011), where we have presented the preliminary calculations and comparison with the Boudifa model. The main differences between these models are related to the damage modeling (number of scales, evolution equation, coupling), the localization tensor, and the kind of plastic hardening. It was concluded that the numerous parameters of the thermodynamic model of Boudifa cannot be unambiguously identified, while the parameters of the new model can be found out for the damage process occurring before sample fracture. It should be highlighted that our previous model calculations (Panicaud et al., 2011) were compared with macroscopic stress vs. sample strain dependence with the assumption that damage occurs only in the ferritic phase. As it will be shown in this work, this assumption can be proved only by using the diffraction measurements in which the load distribution between phases can be determined. Moreover, the diffraction results provide information about the initiation of damage processes occurring for much smaller deformation than for sample fracture.

It should also be mentioned that an alternative method for prediction of damage at a microscale of polycrystalline materials has been proposed and used in finite element calculations by Rousselier and Luo (2014). In this approach Mohr-Coulomb model (Mohr, 1900) based on a ductile fracture model was applied at the slip system scale. The calculations were also performed combining plasticity of porous material (a void damage model) with the Mohr-Coulomb model and Portevin and Le Chatelier model for ductile fracture analyses (Rousselier and Quilici, 2015). Similar to the Boudifa model, the calculations were done using a 'Reduced Texture Methodology' and they are limited to a small number of grains (e.g. 12 crystallites for single phase). Therefore, a direct comparison of the theoretical results, which must be obtained for a large population of crystallites, with a diffraction experiment is not possible. Moreover, the isotropic scale transition given by the Cailletaud and Pilvin rule (the same as in the work of Boudifa et al., 2009) was used and the crystal anisotropy was not considered in the calculations. On the contrary, the self-consistent method based on the Eshelby approach (Panicaud et al., 2011) can be used to predict stress distribution between a large number of crystallites taking part in diffraction experiments. This model enables taking into account the elastic anisotropy of the grains as well as the anisotropic localization of strain/stress rates in the polycrystalline grain. 
The literature review presented above shows that, except of the self-consistent approach proposed in the work of Panicaud et al. (2011), such effects as the anisotropy of crystal elasticity, plasticity occurring due to slips on crystallographic planes and anisotropy of intergranular interaction were not introduced simultaneously in the damage models. Also, it has been stated in many papers that the fraction of the damaged grains leads to a loss of stress carrying capacity (e.g. Gonzàlez and LLorca, 2000; Tekoğlu and Pardoen, 2010) or grain softening (Boudifa et al., 2009), and consequently causes a decrease of the stress localized in these grains. The decrease of the stress in damaged ferritic grains within duplex steel was observed experimentally using diffraction measurement during an in situ uniaxial tensile loading (M'Cirdi et al., 2001; Istomin et al., 2014), however these experimental data were never compared to theoretical models. In most of the published works, usually the predicted overall stress-strain curve was compared with the measured one (e.g. for a tensile test) but the stresses for particular grains, groups of grains or phases were not verified experimentally. One of the main issues of the present work is to describe the localization of stresses on the damaged grains using our model proposed in the work of Panicaud et al. (2011), and to verify the theoretical results using diffraction experiments. In the latter work the equations for stress and strain localization tensors are derived in the frame of the self-consistent model formulated by Lipinski and Berveiller (1989). Our method takes into account the local elastoplastic properties of grains having different lattice orientations. It allows for calculating the evolution of the stress and of the lattice orientation for a large number of crystallites. Therefore the variation of the stresses predicted for groups of damaged grains can be directly compared with the results of diffraction experiment.

The material chosen for this studied is a two-phase duplex stainless steel which was examined in detail for small deformation and undamaged state in our previous works (Baczmański and Braham, 2004; Baczmański et al., 2011), where the agreement between self-consistent predictions and neutron diffraction data was shown. In the present work the methodology combining self-consistent model with diffraction experiment will be applied to study the elastoplastic behavior of the phases in duplex steels having different chemical compositions and/or subjected to different thermal treatments. As shown by M'Cirdi et al., 2001; Haušild et al., 2001; Balbi et al., 2009; Prahl et al., 2010, the initiation of a damage process in the aged duplex steel occurs on slip planes and/or on the other particular crystallographic planes. This process can cause the reduction of the grain stress, leading to decrease of lattice elastic strains and this effect depends on the grain orientation (M'Cirdi et al., 2001). In the present article it will be shown experimentally (using neutron diffraction) that the micro-damage is first initiated in the grains of ferrite and the effect of elastic lattice strain reduction depends on the orientations of the grains contributing to a given reflection $h k l$. The effect of stress relaxation will be interpreted using the self-consistent approach, which enables prediction of the micro-damage initiation and its evolution in two-phase materials.

\section{Elastoplastic model coupled with damage process}

The results of diffraction experiments performed in this work are analyzed with the help of a self-consistent model elaborated by Lipinski and Berveiller (1989). This model was adapted for prediction of lattice strains in duplex steels by Baczmański and Braham (2004). Then, the methodology was developed in order to predict the process of micro-damage occurring at the grain scale (Panicaud et al., 2011).

\subsection{Self-consistent model for elastoplastic deformation}

The used self-consistent model enables calculations at two different scales, i.e. the macro scale, where the macrostress and macrostrain $(\underline{\Sigma}, \underline{E})$ are applied, and the local scale, on which the deformation of the gth grain under local stress $\underline{\sigma}^{g}$ is considered. Plastic deformation of a grain occurs due to the slips on these crystallographic planes for which Schmid's law is fulfilled, i.e. the resolved shear stress $\tau$ is equal to its critical value $\tau_{c}^{s}$ (named critical resolved shear stress - CRSS). During slip the dislocations density increases and this process leads to hardening of all slip systems in a given grain. As a consequence, the values of CRSS increase with deformation and the rate of $\tau_{c}^{s}$ for a given $s$-th system can be expressed by:

$$
\dot{\tau}_{c}^{s}=\sum_{t} H^{s t} \dot{\gamma}^{t}
$$

where $\dot{\gamma}^{t}$ is the plastic glide rate on the $t$-th active system, $H^{\text {st }}$ is the hardening matrix defining interactions between the slip systems and dot denotes time derivative.

To describe nonlinear evolution of hardening the Voce law can be used (Tome et al., 1984; Jia et al., 2008; Neil et al., 2010). In this law the reference CRSS $\tau_{\text {Voce }}^{g}$ in a grain $g$ depends on the plastic shear strain accumulated on all systems $\vartheta^{g}$ according to the relation:

$$
\left.\tau_{\text {Voce }}^{g}=\tau_{0}^{p h}+\left(\tau_{1}^{p h}+\theta_{1}^{p h} \vartheta^{g}\right)\left[1-\exp -\frac{\theta_{0}^{p h}}{\tau_{1}^{p h}} 9^{g}\right)\right]
$$
where: $\tau_{0}^{p h}, \tau_{1}^{p h}, \theta_{0}^{p h}$ and $\theta_{1}^{p h}$ are adjusted independently for each phase $p h$ and $\vartheta^{g}=\sum_{t} \gamma^{t}$ is a sum of the total shear strains $\gamma^{t}$
for all active slip systems $t$.

Consequently, in the Voce law the hardening matrix is given by the relation: 


$$
H^{s t}=\frac{\partial \tau_{\text {Voce }}^{g}}{\partial 9^{g}} h^{s t}
$$

Where the 'self' and 'latent' hardenings are defined by the $h^{\text {st }}$ matrix.

To calculate the evolution of the CRSS on a particular slip system, at first the reference value of $\tau_{\text {Voce }}^{g}$ and hardening matrix $H^{\text {st }}$ for a particular grain $g$ must be determined from Eqs. (2) and (3) for a current value of accumulated strain $9^{g}$. Then using Eq. (1), the rate of CRSS for given slip system $s$ is computed from known values of $H^{\text {st }}$ and rates of plastic glides $\gamma^{t}$ on all active systems $t$. In the present work it is assumed that the 'self and 'latent' hardenings are equal, i.e. $h^{\text {st }}=1$ for each pair $s$ and $t$ of the slip systems.

To obtain macroscopic predictions of elastoplastic deformation for polycrystalline material, it is useful to perform a scale transition method. In this model, the constitutive equation relating stress rate with strain rate is written for the local scale and the global scale as well:

$$
\underline{\dot{\underline{\sigma}}}^{g}=\underline{\underline{l}}^{g}: \underline{\dot{\varepsilon}}^{g} \text { and } \underline{\dot{\Sigma}}=\underline{\underline{L}}: \underline{\dot{E}}
$$

where $\underline{\underline{g}}^{g}, \dot{\sigma}^{g}, \dot{\underline{\varepsilon}}^{g}$ denote, respectively, tensors of tangent moduli, stress rate and strain rate, while the capital letters $\underline{\underline{L}, \dot{\Sigma}}, \underline{\dot{E}}$ are used for the same tensors but defined at the macroscopic scale.

The scale transition is defined by the equation:

$$
\underline{\dot{\varepsilon}}^{g}=\underline{\underline{A}}^{\mathrm{g}}: \underline{\dot{E}}
$$

in which, the grain strain rate $\dot{\varepsilon}^{g}$ is related to overall macrostrain rate $\dot{E}$ through the localization tensor $A^{g}$.

In this work, the localization tensor $\underline{\underline{A}}^{g}$ was calculated assuming a spherical shape of inclusions (representing grains) and using the algorithm elaborated by Lipinski and Berveiller (1989). It should be emphasized that in the model used the grain stress and strain (plastic and elastic), CRSS for the operating slips and the orientation of grain lattice are modified during elastoplastic deformation iteratively (i.e. the evolution of crystallographic texture is taken into account in calculations as described by Lipinski and Berveiller (1989)).

\subsection{Damage of the grain}

To predict ductile micro-damage process in the frame of self-consistent model, the assumption of energy equivalence (Saanouni and Abdul-Latif, 1996) was applied at the grain scale. To do this, the effective stress tensor $\tilde{\tilde{\sigma}}^{g}$ and the effective total strain tensor $\underline{\tilde{\varepsilon}}^{g}$ were introduced for a given grain $g$ :

$$
\underline{\tilde{\sigma}}^{g}=\frac{\underline{\sigma}^{g}}{\sqrt{1-d^{g}}} \text { and } \underline{\tilde{\varepsilon}}^{g}=\underline{\varepsilon}^{g} \sqrt{1-d^{g}}
$$

where: $d^{g}$ is a scalar damage variable which describes damage at a grain scale.

It is assumed that in the equivalent fictive undamaged grain, the tangent moduli tensor $\underline{l}^{g}$ of undamaged material relates the effective rate of the stress $\underline{\dot{\tilde{\sigma}}}^{g}$ to the effective rate of total grain strain $\underline{\dot{\tilde{\varepsilon}}}^{g}$. Then, constitutive relations can be postulated for the stress and strain rates defined for the undamaged and damaged grains, respectively (Panicaud et al., 2011):

$$
\underline{\dot{\tilde{\sigma}}}^{g}=\underline{\underline{l}}^{g}: \underline{\dot{\tilde{\varepsilon}}}^{g} \Leftrightarrow \underline{\dot{\sigma}}^{g}=\underline{\tilde{l}}^{g}: \underline{\dot{\varepsilon}}^{g}
$$

where $\underline{\underline{l}}^{g}$ is the tangent moduli tensor for the damaged grain.

In general case when $d^{g}=f\left(\underline{\varepsilon}^{g}, \underline{\sigma}^{g}, \underline{\dot{\varepsilon}}^{g}, \underline{\dot{\sigma}}^{g}\right)$ in Eq. (6) depends on total strain and stress tensors, the expression for tensor can be derived (Panicaud et al., 2011):

$$
\underline{\underline{\tilde{l}}}^{g}=\left(\underline{\underline{1}}+\frac{1}{2}\left(\underline{\underline{l}}^{g}: \underline{\varepsilon}^{g}+\frac{\underline{\sigma}^{g}}{1-d^{g}}\right) \otimes \frac{\partial d^{g}}{\partial \underline{\sigma}^{g}}\right)^{-1}:\left(\left(1-d^{g}\right) \underline{\underline{l}}^{g}-\frac{1}{2}\left(\underline{\underline{l}}^{g}: \underline{\varepsilon}^{g}+\frac{\underline{\sigma}^{g}}{1-d^{g}}\right) \otimes \frac{\partial d^{g}}{\partial \underline{\varepsilon}^{g}}\right)
$$

where $\underline{\underline{1}}$ is the fourth-rank identity tensor.

If the ductile damage occurs, the yielding criterion defined at a microscopic scale must be also modified. In undamaged equivalent grain, small shear strains $\tilde{\gamma}^{t}$ on slip systems $t$ cause an increase of the CRSS for the $s$ system according to the linear relation (cf. Eq. (1)):

$$
\tilde{\tau}_{c}^{s}=\tau_{0}^{s}+\sum_{t} H^{s t} \tilde{\gamma}^{t}
$$

where $H^{s t}$ are the components of hardening matrix and $\tau_{0}^{s}$ is the initial value of CRSS for the slip system $s$. For nonlinear hardening, the component of $H^{s t}$ is calculated from the Voce law using Eqs. (2) and (3), with the sets of parameters separately defined for each $p h$-phase of the polycrystalline aggregate. 
Assuming that the microscopic damage on the slip system is described by the function $d^{g}$ (equal for whole grain $g$ ) the effective slip $\tilde{\gamma}^{t}$ and the CRSS $\tilde{\tau}_{C}^{s}$ can be defined for the equivalent undamaged material (in the same way as in Eq. (6)):

$$
\tilde{\gamma}^{t}=\gamma^{t} \sqrt{1-d^{g}} \text { and } \tilde{\tau}_{c}^{S}=\frac{\tau_{c}^{S}}{\sqrt{1-d^{g}}}
$$

Substituting Eq. (10) into Eq. (9), and differentiating the obtained equation, the rate of CRSS in the damaged material can be determined:

$$
\begin{aligned}
\dot{\tau}_{c}^{s} & \left.=\left(1-d^{g}\right) \sum_{t} H^{s t} \dot{\gamma}^{t}-\frac{1}{2} \quad 2 \sum_{t} H^{s t} \gamma^{t}+\frac{1}{\sqrt{1-d^{g}}} \tau_{0}^{s}\right) \dot{d}^{g} \\
& \left.=\left(1-d^{g}\right) \sum_{t} H^{s t} \dot{\gamma}^{t}-\frac{1}{2} \quad \sum_{t} H^{s t} \gamma^{t}+\frac{1}{1-d^{g}} \tau_{c}^{s}\right) \dot{d}^{g}
\end{aligned}
$$

Finally, to describe micro-damage process occurring in the grain $g$ the variation of the $d^{g}$ function has to be established. In the present article it was assumed that $d^{g}$ function depends only on the grain strain and an isotropic damage evolution at the grain scale is defined by $\dot{d}^{g}$ rate according to the following relation:

$$
\dot{d}^{g}=\xi^{p h}\left(\varepsilon_{e q}^{g}-\varepsilon_{0}^{p h}\right)_{+}^{\eta^{p h}}\left(\dot{\varepsilon}_{e q}^{g}\right)_{+}
$$

where: $\varepsilon_{0}^{p h}, n^{p h}, \xi^{p h}$ are phase-dependent parameters defined for a given phase $p h, \underline{\varepsilon}_{e q}^{g}=\sqrt{\frac{3}{2}\left(\underline{\varepsilon}^{g}-\frac{1}{3} \operatorname{tr}\left(\underline{\varepsilon}^{g}\right) \underline{1}\right):\left(\underline{\varepsilon}^{g}-\frac{1}{3} \operatorname{tr}\left(\underline{\varepsilon}^{g}\right) \underline{1}\right)}$ is the second invariant of the total strain tensor for a grain $g,(\ldots)_{+}$are the Macaulay brackets, which denote the positive part of the variable $x$, i.e. $(x)_{+}=x$ if $x>0$ and $(x)_{+}=0$ if $x \leq 0$.

In our previous work (Panicaud et al., 2011), an equivalent integral equation was used to directly define the value of the damage function $d^{g}$. The new formulation of the $d^{g}$ rate used in this work enables the introduction of additional conditions concerning damage development. The application of the Macaulay brackets causes that a negative strain rate, i.e. $\dot{\varepsilon}_{e q}^{g}<0$ (occurring in the material for a compressive loading) will never lead to damage, and the damage function $d^{g}$ only increases if the strain is superior to the strain threshold $\varepsilon_{0}^{p h}$ defined for each phase separately. Moreover, the damage function will never decrease even for a decreasing equivalent strain (due to the elastic unloading of a given grain).

It should be highlighted that the defined above damage dg variable is not derived from dissipation potential, as usually in the thermodynamic approaches (e.g. Abu Al-Rub and Voyiadjis, 2003; Brünig, 2003; Egner and Skoczeń, 2010; Murakami, 2012), but it represents a phenomenological function depending on parameters determined from the experiment. This approach is similar to the description of the work hardening through the Voce law in the case of plastic deformation, when hardening of slips is related to the total plastic shear strain accumulated on all active systems operating in a given grain (Eq. (2)). In the case of ductile damage we postulate dependence of function $d^{g}$ on the second invariant of the total strain tensor computed for the considered grain. This function and its parameters will be verified experimentally. The formulation of damage presented above can be easily used in the self-consistent model, which is commonly used to interpret results of the diffraction measurements. Moreover, the approach based on Eq. (12) does not significantly increase the number of unidentified model parameters, as for instance in the case of the model proposed by Boudifa et al., 2009 (c.f. Panicaud et al., 2011). The simplicity of our model is an important advantage which will allow us to determine all model parameters from the diffraction experiment.

\subsection{Strain localization in damaged grains}

When the damage is initiated in the polycrystalline grains the scale transition model must be modified. To do this the strain rate for a damaged grain $\underline{\dot{\varepsilon}}^{g}$ should be related to the macroscopic strain rate of the damaged polycrystalline material $\underline{\dot{E}}$ using strain localization tensor $\underline{\underline{\tilde{A}}}^{g}$ :

$$
\underline{\dot{\varepsilon}}^{g}=\underline{\underline{\tilde{A}}}^{g}: \underline{\dot{E}}
$$

Assuming that the damage depends only on the strain and strain rates the localization tensor for the damaged material is calculated from the equation (for details see Panicaud et al., 2011):

$$
\left.\underline{\underline{\tilde{A}}}^{g}=\left(\left(\sqrt{1-d^{g}}\right) \underline{\underline{1}}-\frac{\underline{\varepsilon}^{g}}{2 \sqrt{1-d^{g}}} \otimes \frac{\partial d^{g}}{\partial \underline{\underline{g}}^{g}}\right)^{-1}: \underline{\underline{A}}^{g}: \quad \sum_{g} x^{g}\left(\left(\sqrt{1-d^{g}}\right) \underline{\underline{1}}-\frac{\underline{\varepsilon}^{g}}{2 \sqrt{1-d^{g}}} \otimes \frac{\partial d^{g}}{\partial \underline{\varepsilon}^{g}}\right)^{-1}: \underline{A}^{g}\right)^{-1}
$$

where $\underline{\underline{A}}^{g}$ is the localization tensor for undamaged material and the $d^{g}$ function is defined through Eq. (12). 


\subsection{Anisotropy effects}

In the self-consistent model used for damage prediction, the crystallographic texture is taken into account, i.e. the model sample is represented by grains having different orientations determined from experimental textures. The texture evolves during calculations due to the rotation of crystallite lattice, which is related to the glides on slip systems (Lipinski and Berveiller, 1989). Therefore, the used model predicts the anisotropy evolution of elastic and plastic deformation, both at the macroscopic and the grain scales. The equivalent strain of the grain and consequently the value of damage variable $d^{g}$ (according to Eq. (12)) depends on the orientation of the lattice of a given crystallite relatively to the localized stress and indirectly on the coupling of this grain with anisotropic polycrystalline aggregate given by the localization tensor $A^{g}\left(\underline{A}^{g}\right.$ depends on the $d^{g}$ variable according to Eq. (14)). The damage process at a grain scale influences also the mechanical behavior of the sample because $d^{g}$ variable is used in the homogenization procedure described in Section 2.3. Therefore, the anisotropy of the sample, its evolution, and influence on the damage of the grain is taken into account in our calculations.

The anisotropy of the damage process occurring within a particular grain is not considered in the present version of the model and it could be done if the damage variable is defined at the scale of slip system. However, the parameters of damage defined at the microscale (for example at slip systems) or tensor description of grain damage will lead to a number of additional parameters which cannot be directly identified using diffraction. This is certainly a possible direction of further model development, but the main aim of this work is to show that diffraction allows us to identify all the material parameters of the simplified model, in which the damage variable is defined at the scale of grain.

\section{Experiments}

\subsection{Microstructural characterization of the studied materials}

The experimental study of elastoplastic deformation and damage process was performed on samples of hot rolled duplex stainless steels. The studied steels are composed of ferrite and austenite, with the volume fraction approximately equal to $50 \%$ for each phase. The EBSD orientation maps, presented in Fig. 1, show the elongated austenitic grains divided into small parts with different lattice orientations, and crystallites of the ferrite with almost the same orientations. Two samples were prepared of the UR45N and UR52N steels, for which the chemical compositions are shown in Table 1. For both studied materials, the pole figures (110), (200), (211) and (111), (200), (220) were measured for the ferrite and the austenite using $\mathrm{Cr}$ $\mathrm{X}$-ray diffraction on a Seifert 4 circles diffractometer. Next, the Orientation Distribution Functions (ODFs) were determined from the pole figures for each phase, independently. To this end, the WIMV algorithm (Kallend et al., 1990) was used. The ODFs are shown in Fig. 1, where the orientation of sample coordinate system respectively to the main directions of the rolling process (RD - rolling direction, TD - transverse direction and ND-normal direction) is defined. Significant anisotropy of grains' orientations was found for both phases, and an especially pronounced texture was obtained for the ferrite (see Fig. 2).

ferrite

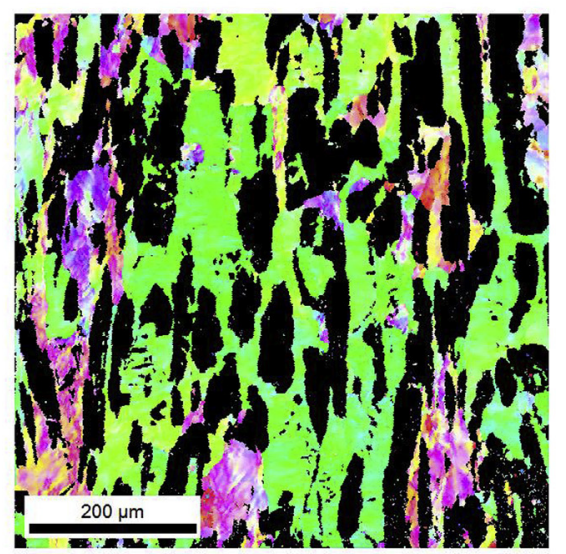

a)

\section{austenite}

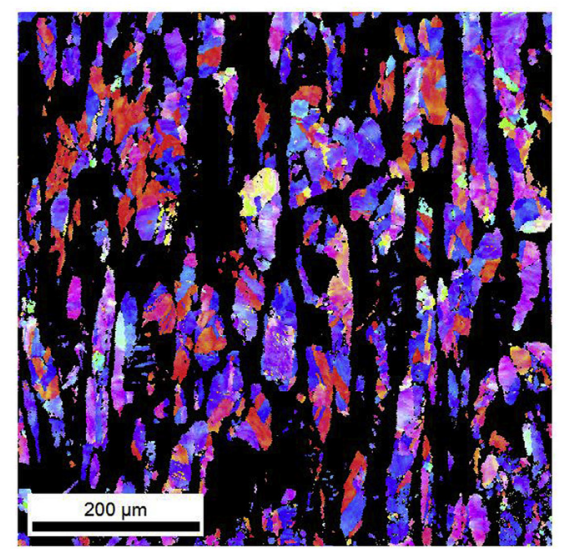

b)
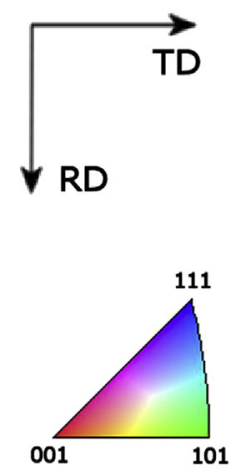

Fig. 1. The EBSD orientation maps showing the microstructure of the UR45N duplex stainless steel. The orientations of the ferritic and austenitic grains are presented by colors in figures (a) and (b), respectively (the unselected phase is black). The sample coordinates are defined by RD (rolling direction) and TD (transverse direction). Different thermal treatments were applied to the studied samples. Two samples of the UR45N and UR52N alloys were heat treated at 1050 ${ }^{\circ} \mathrm{C}$ and then quenched in water, to avoid precipitation of secondary phases. The third sample (of UR $45 \mathrm{~N}$ alloy) was aged during $1000 \mathrm{~h}$ at a temperature of $400^{\circ} \mathrm{C}$ and next cooled in ambient air. (For interpretation of the references to colour in this figure legend, the reader is referred to the web version of this article.) 
Table 1

Chemical composition of the stainless duplex stainless steels: mass-percent (Fe - balance).

\begin{tabular}{llllllll}
\hline & $\mathrm{Cr}$ & $\mathrm{Ni}$ & $\mathrm{Mo}$ & $\mathrm{Mn}$ & $\mathrm{Cu}$ & $\mathrm{N}$ & $\mathrm{C}$ \\
\hline UR45N & 22.4 & 5.4 & 2.9 & 1.6 & 0.12 & 0.17 & 0.015 \\
UR52N & 25.18 & 6.46 & 3.78 & 1.02 & 1.61 & 0.001 \\
\hline
\end{tabular}

\subsection{Neutron and synchrotron diffraction}

\subsubsection{Experimental configurations}

The time of flight (TOF) neutron diffraction was used on the ENGIN-X instrument (Santisteban et al., 2006) at the ISIS neutron spallation source to measure the inter-planar spacings $\langle d\rangle_{\{h k l\}}$ for the studied duplex steels. The diffraction peaks (Fig. 3b) were determined by two detector banks set at scattering angles $2 \theta= \pm 90^{\circ}$ (Fig. 3a). The size of the incident beam was limited by a slit ( $4 \mathrm{~mm}$ wide and $8 \mathrm{~mm}$ high), while the exit aperture of $4 \mathrm{~mm}$ was defined by radial collimators. The tensile test was performed along RD on cylindrical 'dog bone' shaped samples having diameter of 8 mm in the part measured by diffraction (Fig. 3a). Independently for each phase the positions of diffraction peaks were determined and the inter-planar spacings $\langle d\rangle_{\{h k l\}}$ were calculated from Bragg's law. More details concerning the neutron diffraction experiment are given by Baczmański et al. (2011).
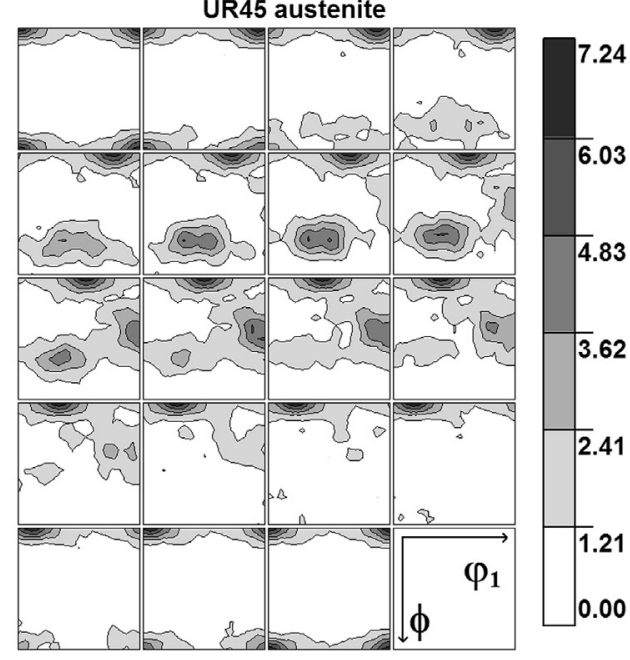

UR52 austenite

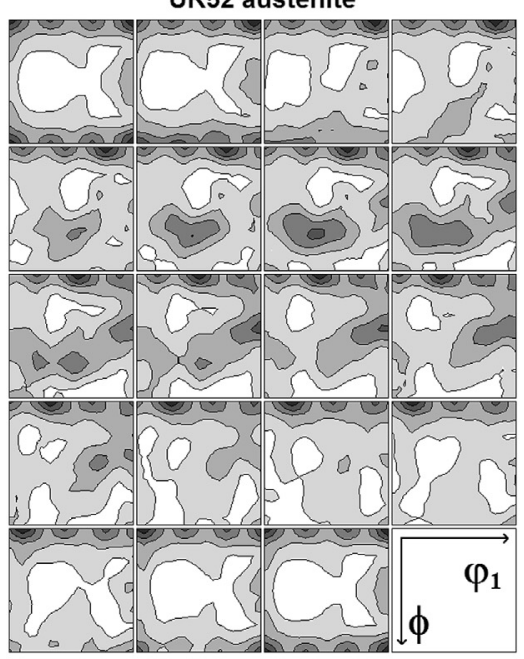

7.24

6.03

4.83

3.62

a)

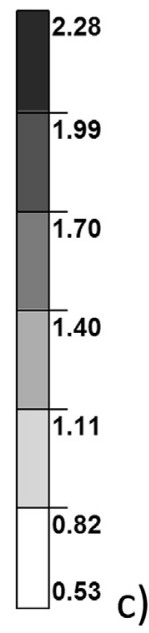

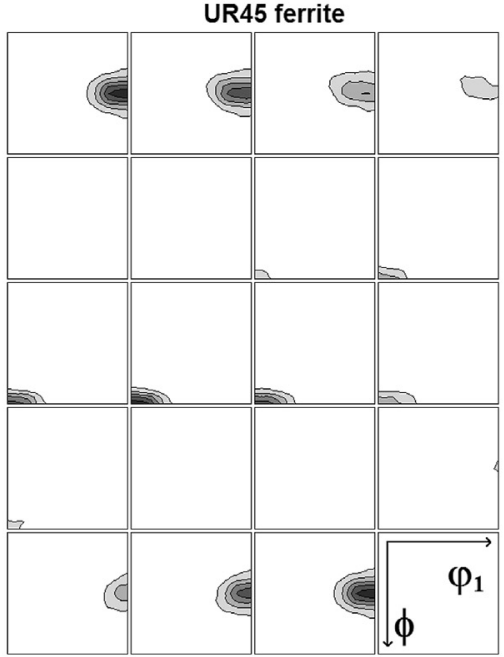

ferrite

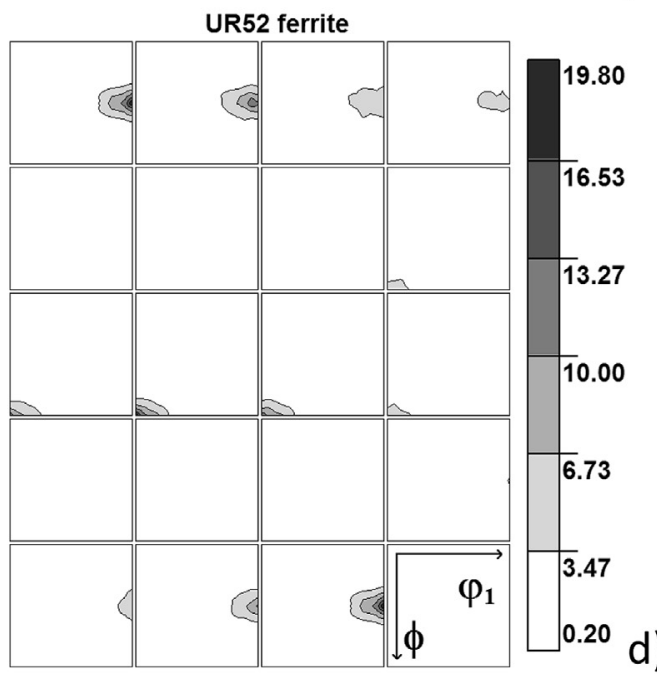

Fig. 2. Textures for austenitic $(a, c)$ and ferritic $(b, d)$ phases in the studied UR45N $(a, b)$ and UR52N (c,d) steels. The ODFs are shown on the cross sections through Euler space, displaced with the increment of $5^{\circ}$ along the $\varphi_{2}$ axis (Kallend et al., 1990). The sample orientation is defined through: $x_{1} \|$ TD, $x_{2} \|$ ND and $x_{3} \|$ RD. 


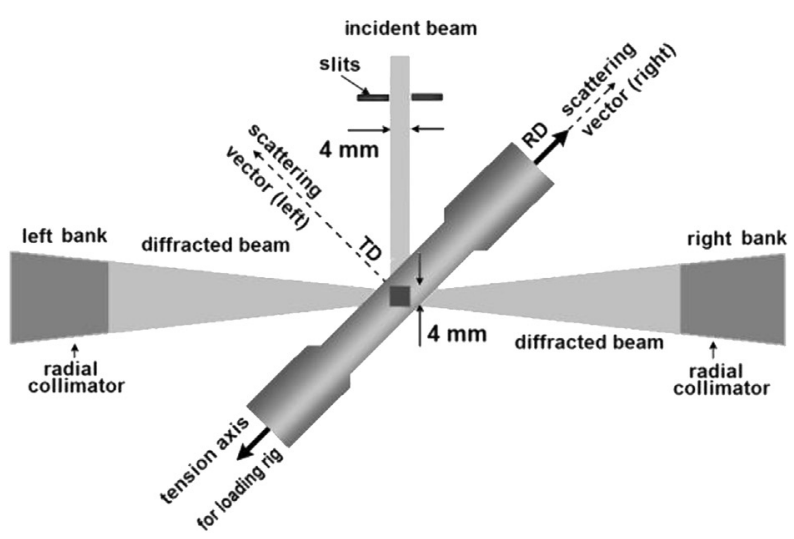

a)

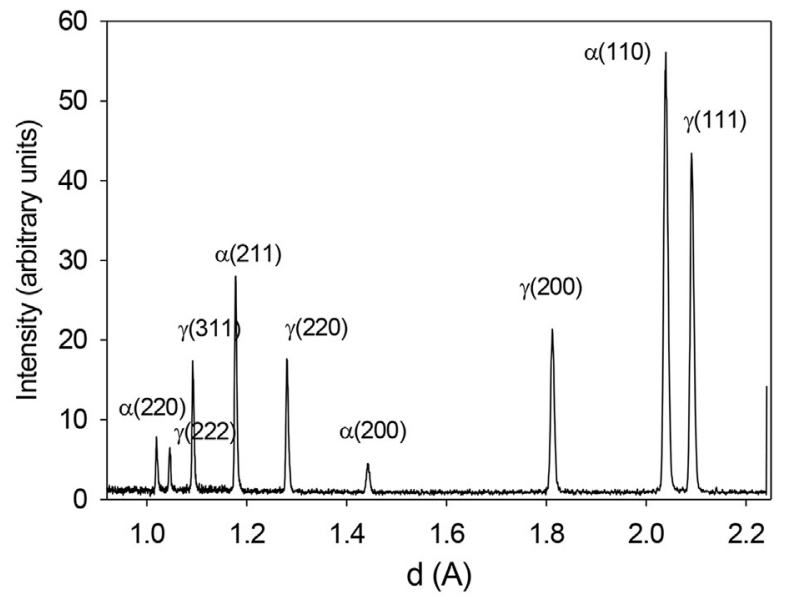

b)

Fig. 3. The experimental setup (ENGIN-X instrument) used to measure relative lattice strains using neutron diffraction during in situ tensile tests (a). In figure (b) the TOF spectrum vs. inter-planar spacing $d$ is shown and the diffraction peaks from $\alpha$-ferrite and $\gamma$-austenite are indicated (b).

Monochromatic X-ray synchrotron radiation (wavelength $\lambda=0.14256 \AA$ ) was also used to measure lattice strains in the aged UR45N duplex steel subjected to a tensile loading along RD. The experiment was conducted at the beamline ID15B (ESRF, Grenoble, France) in a transmission mode using a beam size of $100 \times 100 \mu \mathrm{m}^{2}$ (see Fig. 4a). The cross section of the flat 'dog bone' shaped sample was $1.5 \times 1.5 \mathrm{~mm}^{2}$ in the measured region. Two dimensional diffraction patterns, measured in the range $2 \theta=1.7^{\circ}-7.5^{\circ}$, were recorded by the Thales PIXIUM 4700 detector.

Using the FIT2D program (Hammersley et al., 1996) the two-dimensional diffraction images recorded by the PIXIUM detector (Fig. 4b) were integrated over the azimuth angle within 'cake shape' sectors and converted into a $2 \theta$ diffractogram. Then, a pseudo-Voigt function was fitted to the measured diffraction profiles and the peak positions were determined with help of the MULTIFIT software (Merkel, 2011). Finally, the $\langle d\rangle_{\{h k l\}}$ inter-planar spacings were calculated from peak positions.

\subsubsection{Neutron diffraction measurements}

At first, the stresses were determined in both phases of the undeformed initial steel samples. To this end, the inter-planar spacings $\langle d\rangle_{\{h k l\}}$ were measured for various scattering vector orientations and for different $h k l$ reflections, using TOF neutron diffraction. The stress analysis was done applying a general multireflection method (for details see Wroński et al., 2007). In calculations the X-ray elastic constants (XEC) obtained by the Kröner-Eshelby approach (Wroński et al., 2007) were used. The XEC were determined from the typical single crystal elastic constants (Table 2) and the experimental crystallographic textures of ferrite and austenite (Fig. 2). When using the multireflection method, the deviatoric part of the stress tensor has been determined independently for each phase of the studied steels (Table 3 ). The measured $<d>$ \{hkl\} spacings were satisfactorily fitted using the Kröner-Eshelby approach of XEC, as in the previous work by Wroński et al. (2007)).

Next, the strains of crystallites' lattice were determined using neutron diffraction for the in situ loaded samples. The measurements were done along the applied force (parallel to RD) and in the transverse direction (parallel to TD) for given constant sample stresses/strains when the load subjected to the sample stabilized (Dakhlaoui et al., 2007; Baczmański et al. 2011). Finally, for different $h k l$ reflections the relative values of elastic lattice strains $<_{R D}>_{\{h k l\}}$ and $<_{T D}>_{\{h k l\}}$ are computed:

$$
<\varepsilon_{R D}>_{\{h k l\}}=\frac{<d_{R D}^{\Sigma}>_{\{h k l\}}-<d_{R D}^{0}>_{\{h k l\}}}{<d_{R D}^{0}>_{\{h k l\}}} \text { and }<\varepsilon_{T D}>_{\{h k l\}}=\frac{<d_{T D}^{\Sigma_{1}}>_{\{h k l\}}-<d_{T D}^{0}>_{\{h k l\}}}{<d_{T D}^{0}>_{\{h k l\}}}
$$

where: $\left\langle d^{\Sigma}>_{\{h k l\}}\right.$ and $<d^{0}>_{\{h k l\}}$ are the inter-planar spacings determined for the loaded and non loaded samples and the $<\ldots$ $>_{\{h k l\}}$ brackets denotes an average over the diffracting grains volume for given reflection $h k l$. The load was always applied along the $\mathrm{RD}$, while the strains measurement was done in the RD or TD direction, as indicated by appropriate indices.

The diffraction results for the quenched UR45N (a,b), aged UR45N (c,d) and quenched UR52N (e,f) samples obtained during tensile test are shown in Fig. 5, in which the relative lattice strains along loading direction in function of the applied stress $\Sigma_{R D}$ are presented. The lattice strains were measured separately for different reflections $h k l$ corresponding to the ferritic and the austenitic phases. In the case of large deformation (aged UR45N and quenched UR52N samples), the calibration of the data for large deformation range according to the method proposed by Baczmański et al. (2011) has been done. Additionally, the results for the compressive test performed on the aged UR45N material are shown in Fig. 6 . Finally, the $\Sigma_{R D}$ vs. $E_{R D}$ 

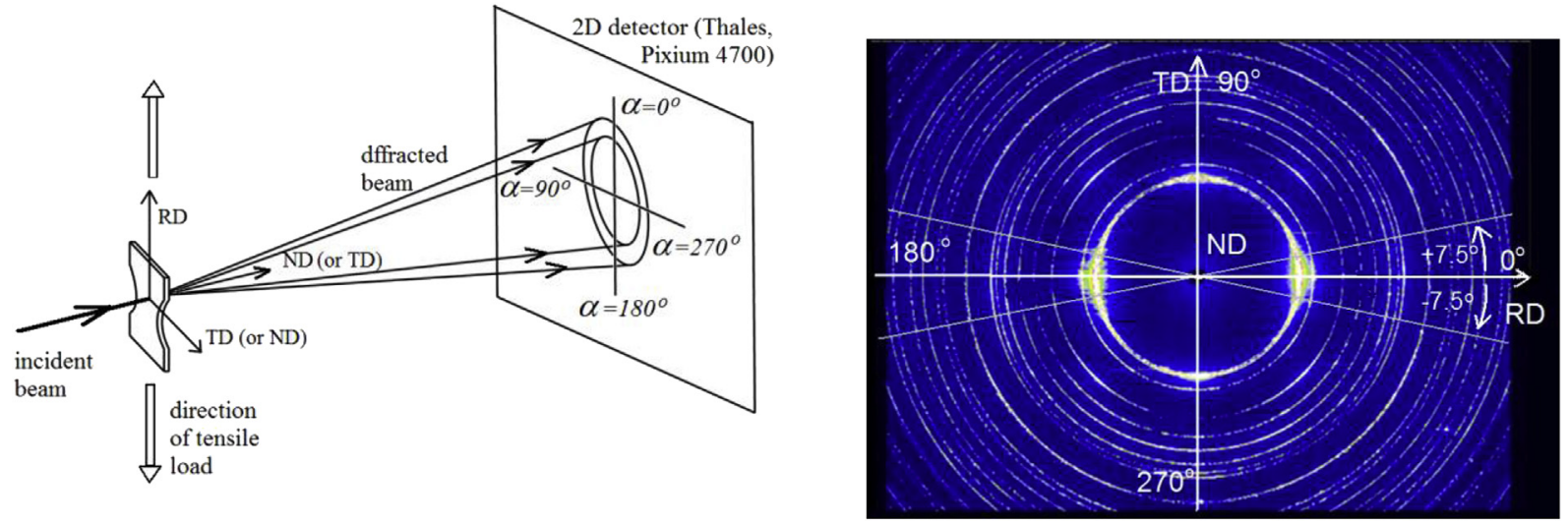

a)

b)

Fig. 4. The synchrotron diffraction experiment performed in the transmission mode at the beamline ID15B using a 2D detector (a) and an example of an image obtained on the CCD detector (b) are shown.

Table 2

Single-crystal elastic constants of ferrite and austenite (Inal et al., 1999).

\begin{tabular}{llll}
\hline Phase & $\mathrm{C}_{11}(\mathrm{GPa})$ & $\mathrm{C}_{12}(\mathrm{GPa})$ & $\mathrm{C}_{44}(\mathrm{GPa})$ \\
\hline Ferrite & 231 & 134 & 116 \\
Austenite & 198 & 125 & 122 \\
\hline
\end{tabular}

Table 3

Phase stresses measured in the undeformed (initial) samples.

\begin{tabular}{llcrrrr}
\hline & & Neutron diffraction (ISIS) & & & \multirow{2}{*}{ Synchrotron (ESRF) } \\
\cline { 3 - 5 } \cline { 3 - 5 } & & UR45N (quenched) & UR45N (aged) & UR52N (quenched) & UR45N (aged) \\
\hline$\sigma_{R D}(\mathrm{MPa})$ & Austenite & $61.1 \pm 12.2$ & $87.3 \pm 9.5$ & $85.4 \pm 10.1$ & $134.1 \pm 15.8$ \\
$\sigma_{T D}(\mathrm{MPa})$ & Ferrite & $-50.3 \pm 15.3$ & $-57.5 \pm 11.3$ & $-24.6 \pm 15.6$ & $-155.5 \pm 19.2$ \\
& Austenite & $59.4 \pm 12.5$ & $-7.1 \pm 9.5$ & $50.3 \pm 10.3$ & $84.3 \pm 15.4$ \\
$\sigma_{N D}(\mathrm{MPa})$ & Ferrite & $-29.4 \pm 15.2$ & $-19.2 \pm 12.2$ & $-122.7 \pm 15.7$ & $-44.4 \pm 19.6$ \\
& Austenite & $-120.3 \pm 12.6$ & $-80.7 \pm 9.6$ & $-135.1 \pm 10.2$ & $-218.2 \pm 15.3$ & $199.4 \pm 18.1$ \\
\hline
\end{tabular}

(macrostress vs. macrostrain) plots, obtained using a load cell sensor and a strain gauge during diffraction experiment, are presented in Fig. 7.

\subsubsection{Synchrotron measurements}

To determine initial stresses from synchrotron diffraction, the inter-planar spacings $\left\langle d>_{\{h k l\}}\right.$ were determined for two orientations of the initial samples. Both orientations are shown in Fig. 4a, where the RD, ND, and TD are indicated for the first orientation without brackets and for the second one with brackets (specimen was rotated by $90^{\circ}$ around RD). The intensities of the diffraction rings, corresponding to different reflections $h k l$ were integrated within 'cake shape' sectors $\alpha_{n} \pm 7.5^{\circ}$ (Fig. 4b), where $\alpha_{n}$ changes with steps of $15^{\circ}$ over the whole $360^{\circ}$ range of the azimuth angle. Next, for every reflection $h k l$ the inter-planar spacings $\langle d>\{h k l\}$ were measured for 24 scattering vector orientations. Finally, we have calculated the arithmetical mean $\langle d\rangle_{\{h k l\}}$ spacings for symmetrically equivalent $\alpha_{n}$ and $\alpha_{n}+180^{\circ}$ angles. The initial stresses in each phase were determined using the multireflection method (the same XEC as for neutron measurements were used in the analysis). As a result, the deviatoric part of the stress tensors was calculated independently for each phase (see Table 3). Almost equal absolute values of stress components but with opposite signs were found for austenite and ferrite, i.e. stresses are balanced over both phases having equal volume fractions.

The 'dog bone' shaped samples were measured during uniaxial in situ tensile loading. The force along RD, applied using a hydraulic $5 \mathrm{kN}$ rig, was increased in the load control mode with a rate of $1 \mathrm{~N} / \mathrm{s}$ (corresponding to stress rate of $0.44 \mathrm{MPa} / \mathrm{s}$ ) and the total sample deformation was determined from the measured actuator position. The macro-mechanical $\Sigma_{R D}$ vs. $E_{R D}$ plot obtained during tensile test is shown in Fig. 8. Diffraction patterns were registered during time of exposition equal to $10 \mathrm{~s}$ with interval time of $5 \mathrm{~s}$. The inter-planar spacings along the loading direction (RD, $\alpha=0^{\circ}$ and $180^{\circ}$ ) and in the perpendicular 


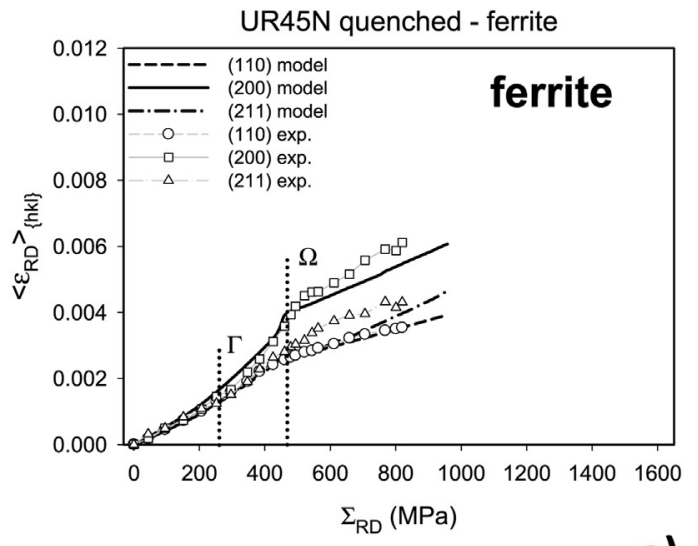

a)

\section{UR45N aged}

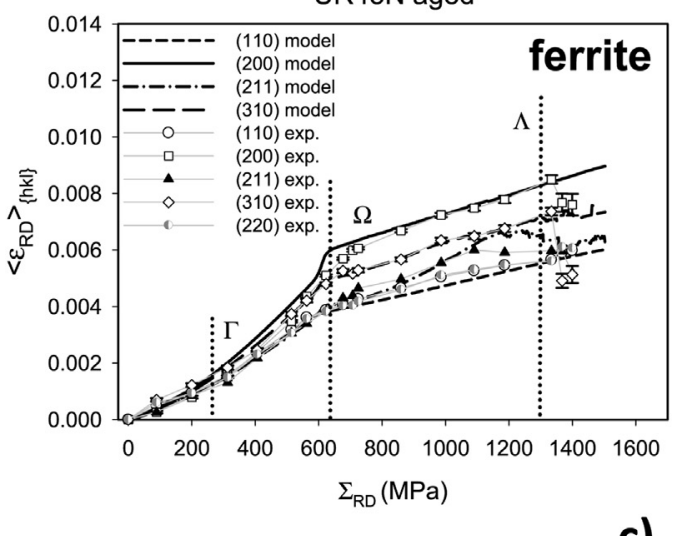

c)
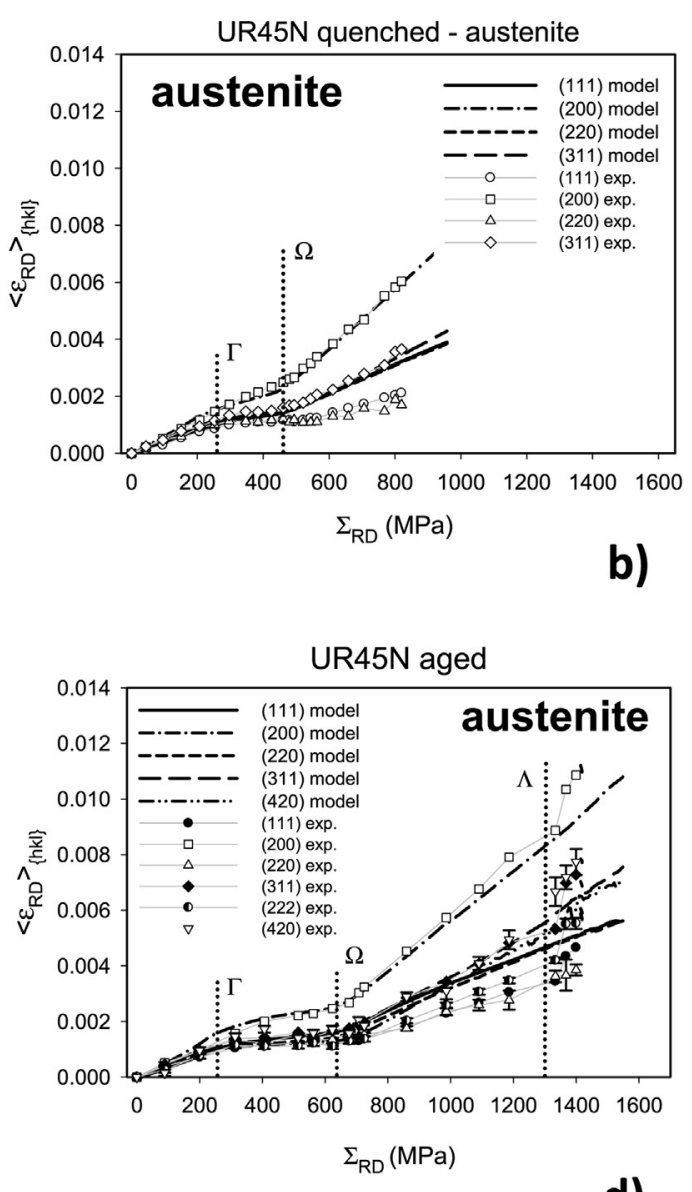

d)

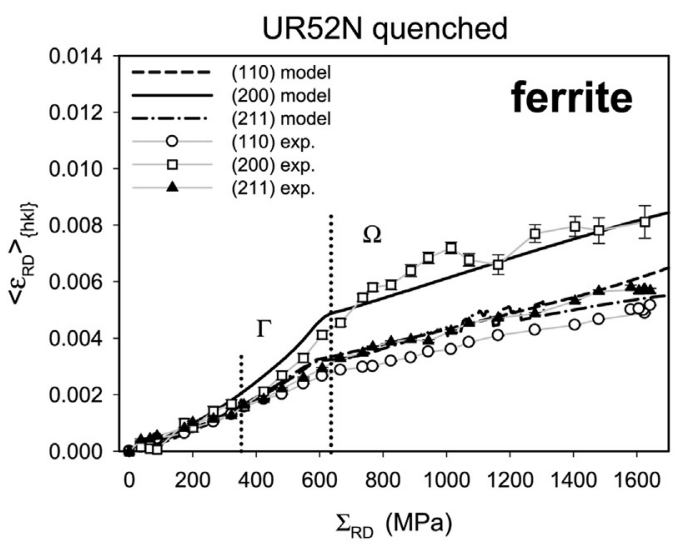

e)

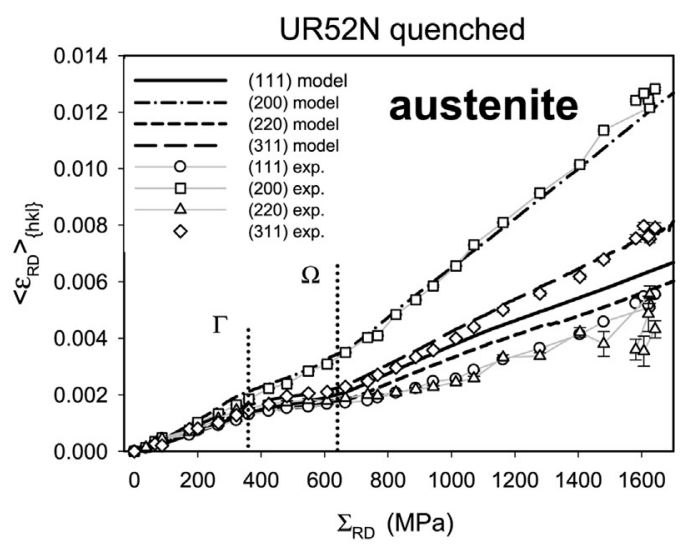

f)

Fig. 5. Values of relative elastic lattice strains $\left(<_{R D}>\{h k l\}\right)$ along the loading direction (RD) in function of the macrostress $\Sigma_{R D}$ for quenched UR45N (a,b), aged UR45N (b,c) and quenched UR52N (e,f) samples. Experimental results (symbols) determined during tensile tests and results of model simulations (lines) are compared. The thresholds $T$ and $\Omega$ indicate the plastic yield of austenite and ferrite, respectively.

direction (TD, $\alpha=90^{\circ}$ and $270^{\circ}$ ) were determined. For this purpose, the intensities of the diffraction rings were integrated within 'cake shape' sectors defined by $\alpha \pm 7.5^{\circ}$ (Fig. 4). Finally the arithmetical mean values of the spacings $\langle d\rangle_{\{h k l\}}$ were 

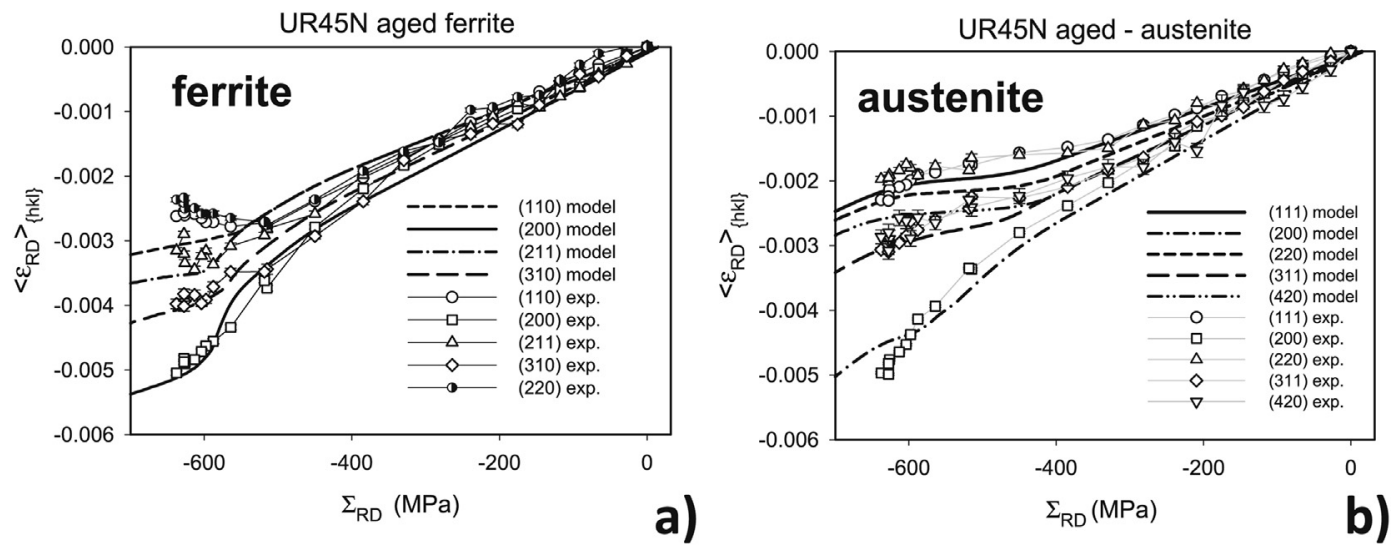

Fig. 6. Values of the measured relative lattice strains $\left\langle\varepsilon_{R D}\right\rangle_{\{h k l\}}$ vs. $\Sigma_{R D}$ for the aged UR45N specimen (symbols) compared with the predictions (lines). The compressive test along RD was performed.
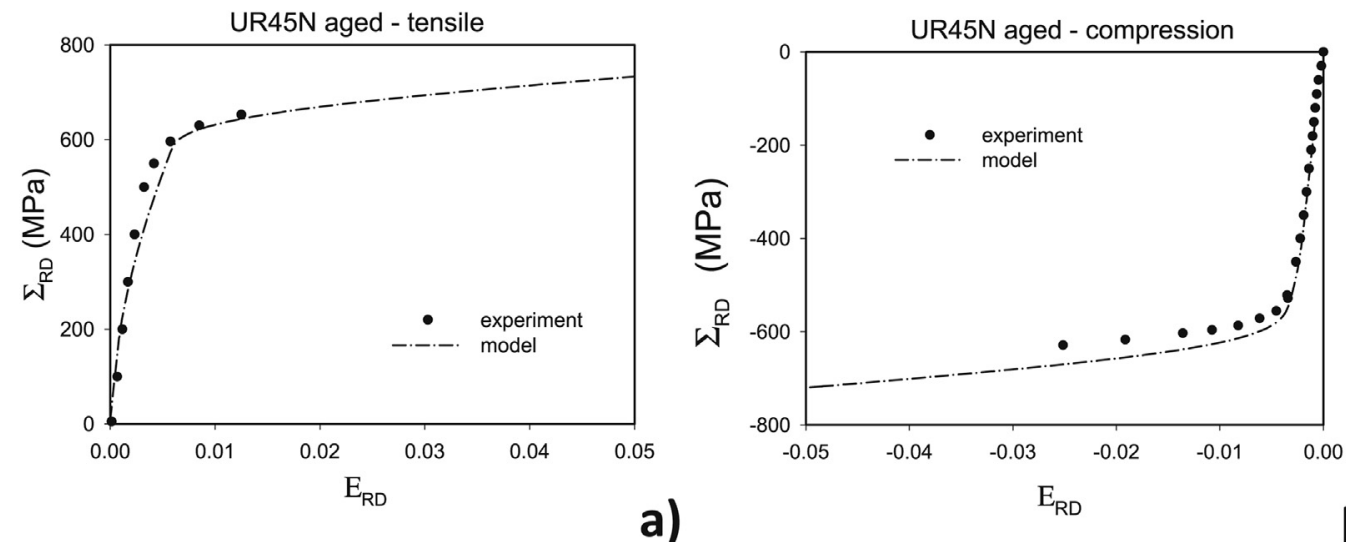

a)
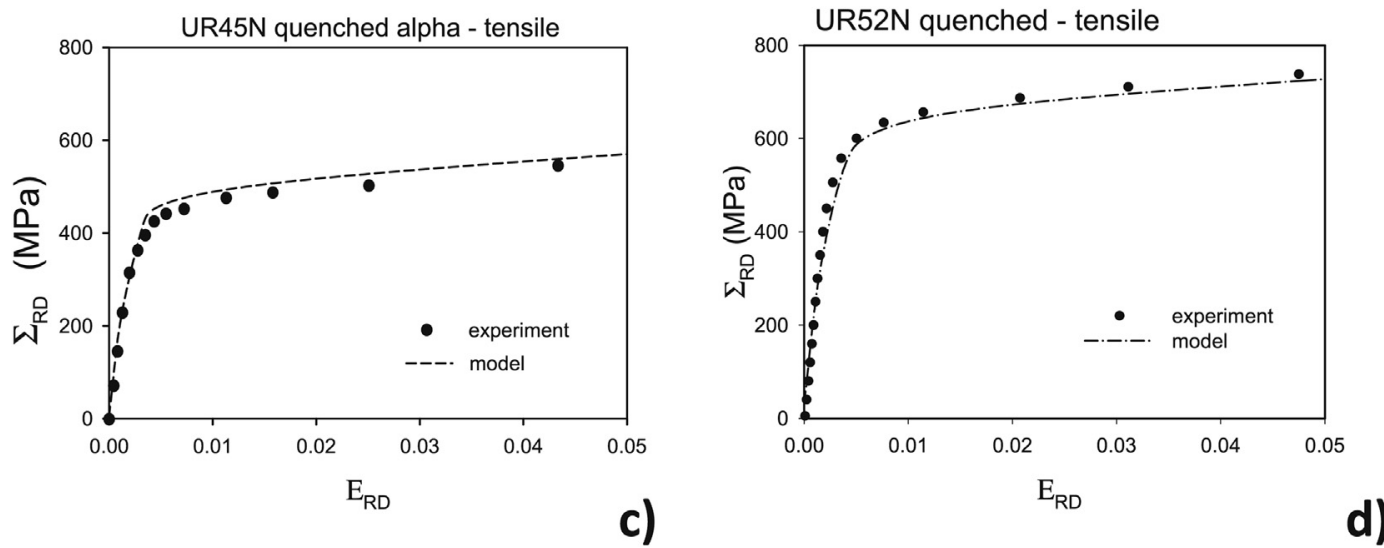

Fig. 7. Macro-mechanical stress $\Sigma_{R D}$ vs. $E_{R D}$ Plots for the aged UR45N steel subjected to tensile (a) and compressive tests (b); and for tensile tests performed on the quenched UR45N (c) and UR52N (d) samples. Experimental results (symbols) determined for small deformation range are compared with model simulations (lines).

calculated for symmetrically equivalent $\alpha$ and $\alpha+180^{\circ}$ angles and the relative lattice strains $\left\langle\varepsilon_{R D}>_{\{h k l\}}\right.$ and $\left\langle\varepsilon_{T D}>_{\{h k l\}}\right.$ were computed in the same way as for the neutron diffraction measurements (see Eq. (15)). It should be noticed that a small gauge volume used for synchrotron measurements $(100 \mu \mathrm{m} \times 100 \mu \mathrm{m})$ decreases significantly the number of diffracting grains in comparison with a neutron diffraction experiment $(4 \mathrm{~mm} \times 4 \mathrm{~mm})$. Therefore, due to a smaller number of grains contributing to diffraction for a given $h k l$ reflection, the lattice strains $\left(<\varepsilon_{R D}>\{h k l\}\right.$ and $\left\langle\varepsilon_{T D}>\{h k l\}\right)$ measured with synchrotron radiation are less representative. To overcome this problem, the arithmetic mean values $\left\langle\varepsilon_{R D}>p h\right.$ (and $\left\langle\varepsilon_{T D}>p h\right.$ ) were calculated for the 


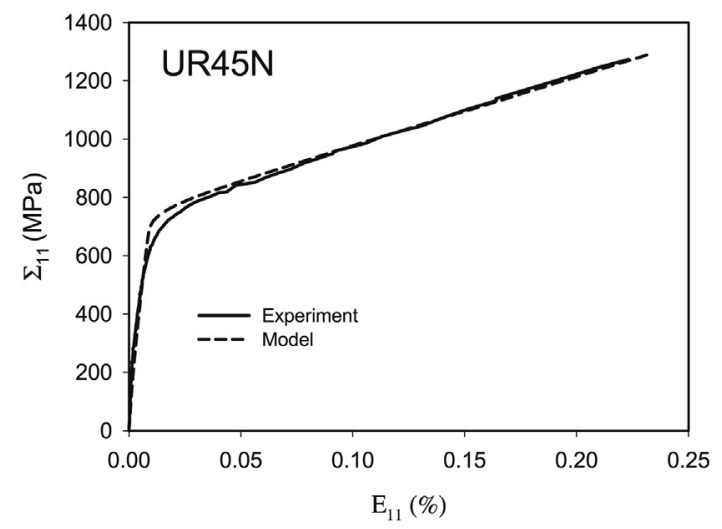

Fig. 8. Mechanical tensile curve obtained during synchrotron measurements (solid line) and model predicted function (dashed line) are compared for the aged UR45N duplex steel.

austenite (over 111, 200, 220, 222, 400 and 331 reflections) and for the ferrite (over 110, 200, 211, 220 and 310 reflections). In Fig. 9, the so obtained mean phase strains are shown in function of the applied macrostress $\Sigma_{R D}$.

\section{Discussion and interpretation of the experimental results}

To characterize the elastoplastic deformation of the phases within studied materials the self-consistent model was compared with the experimental results. Moreover, a novel methodology of diffraction data interpretation was used to describe the damage process occurring in the ferritic phase. To achieve such a goal, the developed self-consistent model including damage effect was used (see Section 2).

\subsection{Analysis in the elastoplastic range}

At first, calculations were performed without prediction of the damage effect. This approach allows determination of the parameters of Voce law for both phases in the studied materials. In calculations the starting orientations of grains (determined from the experimental textures; see Fig. 2), single crystal elastic constants (Table 2) and the initial stresses (determined with synchrotron or neutron diffraction techniques; see Table 3) were introduced to the model as the input data. Simulations were done for 20,000 spherical grains belonging either to ferrite $(10,000)$ or to austenite $(10,000)$ phases. As a result, the elastic lattice strains $\left(<\varepsilon_{R D}>\{h k l\}\right.$ and $\left\langle\varepsilon_{T D}>\{h k l\}\right)$ and the total macroscopic sample strains $\left(E_{R D}\right)$ were calculated for different values of the applied stresses $\left(\Sigma_{R D}\right)$.

To identify the values of CRSS for both phases the method proposed by Baczmański and Braham (2004) was used. In this method the predicted strains $\left\langle\varepsilon_{R D}\right\rangle_{\{h k l\}}$ (and additionally $\left\langle\varepsilon_{T D}\right\rangle_{\{h k l\}}$ ) are adjusted to the experimental ones resulting from synchrotron or neutron measurements. To this end, the values of the theoretical and experimental yield points for both
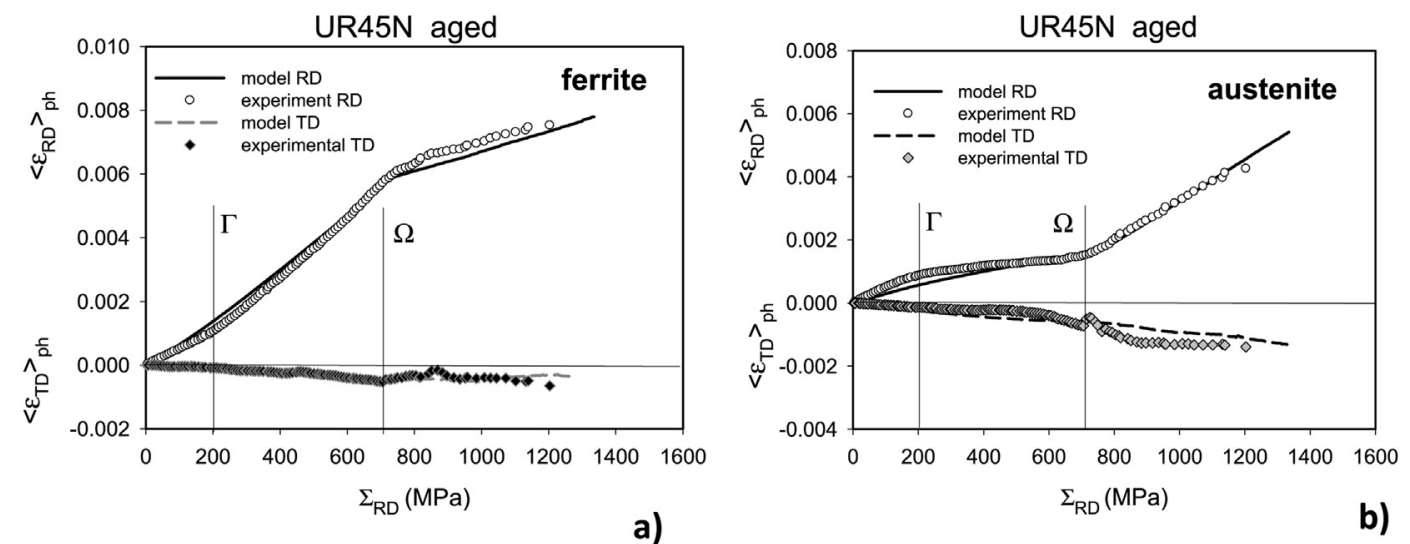

Fig. 9. Mean elastic phase strains vs. applied stress in the UR45N sample for a) ferrite and b) austenite. The experimental results (symbols) were measured along two directions (RD and TD) and compared with theoretically predicted lines (uncertainties are smaller than the symbols representing measured points). The thresholds $\Gamma$ and $\Omega$ indicate the yield points in austenite and ferrite, respectively. 
phases are compared (Baczmański and Braham, 2004; Baczmański et al., 2011). As seen in Figs. 5 and 9, a linear elastic deformation occurs for both phases until $\Gamma$ threshold corresponding to the yield point of the austenitic phase. The next characteristic threshold $\Omega$ in these figures indicates elastic-plastic transition of the ferrite. The position of $\Gamma$ threshold vs. applied stress $\left(\Sigma_{R D}\right)$ enables determination of the initial CRSS $\tau_{0}^{p h}$ for austenite, while the second threshold $\Omega$ allows the initial $\tau_{0}^{p h}$ for ferritic phase to be identified. Fitting of the model results to the experimental data was done simultaneously for the experimental lattice strains (Figs. 5 and 9) and for the $\Sigma_{R D}$ vs. $E_{R D}$ functions (Figs. 7 and 8). It allows determination of the parameters of Voce law $\left(\tau_{1}^{p h}, \theta_{0}^{p h}\right.$ and $\left.\theta_{1}^{p h}\right)$ for each phase, independently (Baczmański and Braham, 2004).

The plastic parameters determined for ferrite and austenite in all the measured samples are gathered in Table 4. In the case of aged UR45N and quenched UR52N, deformed until large deformation range up to the sample fracture (neutron diffraction measurement), all parameters of Voce law were found. Only the initial CRSS $\tau_{0}^{p h}$ and the initial hardening $\theta_{0}^{p h}$ were determined for the other samples, for which almost linear dependence $\Sigma_{R D}$ Vs. $E_{R D}$ was determined in the measuring range, i.e. up to about $25 \%$ of deformation (we assumed that $\tau_{1}^{p h} \rightarrow 0$ and $\theta_{1}^{p h}=\theta_{0}^{p h}$ ). The theoretical results agree with the measurements, both for the lattice strains (Figs. 5, 6 and 9) and for the macro-mechanical result of tensile tests (Figs. 7 and 8). Such agreement proves that the partition of the stresses between phases (and grains) is correctly predicted by the used self-consistent model.

Comparing the results obtained for the UR45N steel subjected to different thermal treatments (see Fig. 5 and Table 4), a considerably lower value of the ferrite yield stress was observed in the quenched material than in the aged one. On the other hand, almost the same yield stress of austenite was found in both samples, regardless of the heat treatment. The ferrite hardness increased during aging due to spinodal decomposition into $\alpha$ and $\alpha^{\prime}$ phases and precipitation of secondary phases (Park and Kwon, 2002). These processes increase the hardness of the UR45N duplex steel compared to the quenched material.

Analyzing the mechanical properties of the quenched UR45N and UR52N steels, subjected to the same thermal treatment but having different composition, we can see that the yield stresses and the initial CRSS ( $\tau_{0}^{\text {ph }}$ in Table 4 ) are higher for both phases in the quenched UR52N duplex steel. Similar results were found using X-ray diffraction by Dakhlaoui et al. (2007), where the higher hardness of ferrite in UR52N steel in comparison to UR45N steel was explained by relatively higher molybdenum and chromium contents in this material (Table 1). Nitrogen increases the hardness of gamma phase, while chromium and molybdenum cause hardening of both phases, but mostly of ferrite (Bugat et al., 2001). Consequently, both phases are responsible for a higher value of macroscopic yield stress for UR52N steel. It was also observed that the rate of work hardening is higher in austenite than in ferrite for all the studied steels (compare $H$ parameter in Table 4). Moreover, the thermal treatment or chemical composition do not influence significantly the hardening of both phases in UR45N and UR52N steels. It means that the differences in the mechanical behavior of the investigated duplex steels are caused mainly through the initial CRSS $\left(\tau_{0}^{p h}\right)$ and the values of initial stresses, but not through the work hardening process.

Finally, an interesting conclusion can be drawn comparing the results of the analysis done for quenched UR52N and aged UR45N samples. Both steels exhibit very similar macro-mechanical behavior, resulting from different micromechanical properties of the phases at microscopic scale. This was clearly shown in the analysis of diffraction results (Fig. 5 and Table 4).

Comparing the results obtained for compressive and tensile tests (Figs. 5c,d and 6) performed on the aged UR45N material, the asymmetry of the lattice strains vs. applied macrostress $\left(\Sigma_{R D}\right)$ functions was found for both phases. However, the macroscopic yield stresses (cf. Fig. 7a,b) and the determined Voce parameters (Table 4) are similar for both modes of deformation. The asymmetry of the phase behavior can be explained through the initial stresses (Table 3 ) present in the phases. Because the tensile stress applied along RD is superposed by the residual stresses, the yield stress of the austenite is lower (due to tensile initial stress in RD), while the ferrite yield stress is higher (due to compressive initial stress in RD), compared to the hypothetical initially stress free material. An opposite effect occurs during compressive tests. Therefore, a more significant difference between the yield stresses of both phases was observed for the tension (Fig. 5c,d) than for the compression (Fig. 6). Despite the mode of deformation, the initial phase stresses increase the elastic limit for one phase and decrease for the second one, by approximately the same value. As a result, the phase stresses do not lead to a significant change of macroscopic yield stress for duplex steel composed of two phases with the same volume fraction (cf. Fig. 7a,b for tensile and compressive uniaxial loads, respectively).

Table 4

Parameters of Voce law determined using diffraction during in situ mechanical tests with uniaxial load applied along RD.

\begin{tabular}{|c|c|c|c|c|c|c|}
\hline & & \multicolumn{4}{|c|}{ Neutron diffraction (ISIS) } & \multirow{3}{*}{$\begin{array}{l}\frac{\text { Synchrotron (ESRF) }}{\text { Aged UR45N }} \\
\text { Tension }\end{array}$} \\
\hline \multicolumn{2}{|l|}{ Material } & \multirow{2}{*}{$\frac{\text { Quenched UR45N }}{\text { Tension }}$} & \multicolumn{2}{|c|}{ Aged UR45N } & \multirow{2}{*}{$\frac{\text { Quenched UR52N }}{\text { Tension }}$} & \\
\hline \multicolumn{2}{|c|}{ Deformation mode } & & Tension & Compression & & \\
\hline \multirow{2}{*}{$\tau_{0}^{p h}(\mathrm{MPa})$} & Austenite & 140 & 140 & 120 & 180 & 150 \\
\hline & Ferrite & 220 & 350 & 360 & 290 & 410 \\
\hline \multirow{2}{*}{$\theta_{0}^{p h}(\mathrm{MPa})$} & Austenite & 225 & 225 & 225 & 225 & 380 \\
\hline & Ferrite & 110 & 110 & 110 & 110 & 190 \\
\hline \multirow[t]{2}{*}{$\tau_{1}^{p h}(\mathrm{MPa})$} & Austenite & not determined & 280 & not determined & 280 & not determined \\
\hline & Ferrite & & 140 & & 140 & \\
\hline \multirow[t]{2}{*}{$\theta_{1}^{p h}(\mathrm{MPa})$} & Austenite & & 6 & & 6 & \\
\hline & Ferrite & & 3 & & 3 & \\
\hline
\end{tabular}


The result obtained using synchrotron radiation for the UR45N sample confirmed that the initial stresses influence the elastoplastic deformation of the individual phases in duplex steel. In this experiment the measurements were performed with a much smaller gauge volume than in the case of neutron diffraction. As a result, a significantly higher values of the initial stress were found in the small gauge defined by the synchrotron radiation beam, compared with those measured by neutrons (Table 3). It means that the studied aged UR45N material is heterogeneous or the conditions during samples preparation were not exactly the same (the aged samples for neutron and synchrotron measurements we prepared separately). Moreover, the values of CRSS obtained for the ferritic phase in both experiments are also different, while no significant difference of $\tau_{0}^{p h}$ was found for austenite (Table 4). The higher value of CRSS for ferrite also causes a higher value of macroscopic yield stress for the sample used in the synchrotron experiment (cf. Figs. 7a and 8).

The disagreement between the quantitative results obtained from neutron and synchrotron measurements can be explained through the difference between the samples and the gauge volumes used in both experiments. The difference of residual phase stresses are caused by temperature gradients generated during sample cooling after aging treatment. Using neutron measurement, the average stress over a large sample volume was determined, while the local stress in the center of the narrow sample was measured using a synchrotron beam. The disagreement between the CRSS of ferrite obtained in both experiments may be caused by differences/heterogeneities of the precipitation process during aging. Although the same aging conditions were applied for both samples, the precipitation process can occur heterogeneously, resulting in differences between local and average values of CRSS in the ferritic phase observed using synchrotron and neutron diffraction methods, respectively. Another possible reason for the differences between the samples is that the specimens used for synchrotron and neutron experiments were machined from different parts of the commercial material and the thermal treatment was also performed separately. It should be noted that in spite of some differences both experiments show the same tendency of material properties evolution occurring during thermal treatment, i.e. the cooling process leads to the same type of stress tensor for both phases, and due to precipitation process, the CRSS increases only in the ferritic phase while remains unchanged in the austenite.

Finally the work hardening process during synchrotron and neutron measurements should be compared. In this case the main difference between the performed tests is the rate of stress (synchrotron experiment) or strain (neutron measurements) applied to the sample. The advantage of synchrotron radiation is a high intensity of the beam enabling short measurements during a continuous tensile test. In the case of neutron measurements, the diffraction measurements were performed over a long time (a few minutes or more of acquisition) at a given constant sample strain. Moreover, the neutron measurements were done after some time (10-15 min) necessary for sample relaxation (the stress decreased with time for constant value of applied sample strain). This is why different macro-mechanical $\Sigma_{R D}$ vs. $E_{R D}$ curves were obtained from continuous tests performed during the synchrotron and neutron measurements. The data obtained from the synchrotron experiment corresponds to the behavior of the material during continuous uniaxial tensile deformation, while the data measured with neutrons corresponds to the sample subjected to a tensile test followed by relaxations at given strains. The parameters of Voce law $\left(\tau_{1}^{p h}, \theta_{0}^{\text {ph }}\right.$ and $\left.\theta_{1}^{\text {ph }}\right)$, provided in Table 4 , show that the work hardening in both phases is much higher in the case of continuous tension of the sample because the stress relaxation does not occur. It should be noted that, whatever the test, the model calculations agree very well with the experimental macroscopic stress-strain curves and for the lattice strains in both phases. The self-consistent approach is thus useful to describe plastic deformation at a grain level and to predict macroscopic and local stresses within a polycrystalline duplex stainless steel.

\subsection{Analysis in the damaging range}

In this section the ductile damage process for large deformation of duplex steel is studied. To this end, the results obtained for aged UR45N and quenched UR52N samples are analyzed. Comparing the diffraction data for both materials (Fig. 5c,d,e,f), it can be seen that, for the quenched UR52N material, the tensile test can be performed and successfully modeled up to a higher stress in comparison with an aged UR45N sample. In the case of quenched UR52N steel, the localization of the stresses in both phases does not change until material fracture (i.e. the trend of $\left\langle\varepsilon_{R D}>\{h k l\}\right.$ vs. $\Sigma_{R D}$ plots remains unchanged and no phase softening or hardening occurs). Different behavior was determined for the aged UR45N specimen at a large sample strain, i.e. over $\Lambda$ threshold as seen in Fig. 5b,c. Fracture of this latter sample occurs under lower applied stress $\Sigma_{R D}$ than in the case of UR52N steel. Moreover, a significant decrease of lattice strains in ferrite and a simultaneous increase of lattice strains in austenite is observed above $\Lambda$ limit for the aged UR45N steel. It indicates an important relaxation of the stress in the ferritic phase, which is balanced by increasing the stress in the austenite. The process above the $\Lambda$ threshold changing the trend of the $<\varepsilon_{R D}>_{\{h k l\}}$ vs. $\Sigma_{R D}$ plots can be identified as a significant softening of the ferritic phase caused by damage occurring at the grain scale. The evolution of lattice strains depends on the measured $h k l$ reflection, i.e. on the orientations of grains contributing to diffraction.

The observed experimental phenomenon can be predicted using our self-consistent model in which the ductile damage process is simulated. Assuming that the damage process occurs only in the ferrite, the model results were fitted to experimental $\left\langle\varepsilon_{R D}>p h\right.$ vs. $\Sigma_{R D}$ plots. In Fig. 12 a, also the theoretical tensile curve $\Sigma_{R D}$ vs. $E_{R D}$ was compared with the experimental one, obtained for a large deformation range applying the method proposed by Le Joncour et al. (2010) and Baczmański et al. (2011). In this method the strains were measured in a deformation neck using the DIC (digital image correlation) technique. In Fig. 10a, the experimental lattice strains in the direction loading direction $\left(\left\langle\varepsilon_{R D}>p h\right)\right.$ are compared with the model calculations performed without and with damage simulation. A good agreement between the experiment and the model prediction was 
obtained for most of the measured diffraction patterns, corresponding to different $h k l$ reflections, if the damage process was predicted. As it is seen above the threshold $\Lambda$ in Fig. 10a, a decrease in the lattice strains (and corresponding stresses) for the ferritic grains and an increase in the lattice strains (and corresponding stresses) for the austenitic grains indicate initiation of the model-predicted damage in the ferritic phase. Also, the strains of the lattice $\left\langle\varepsilon_{T D}\right\rangle_{\{h k l\}}$ measured in the transverse direction are shown together with the results of the damage model in Fig. 10b. The $\left\langle\varepsilon_{T D}\right\rangle_{\{h k l\}}$ strains are correctly predicted by the used model for the elastic and plastic deformations of both phases. Moreover, a rapid change of the $\left\langle\varepsilon_{T D}>\{h k l\}\right.$ vs. $\Sigma_{R D}$ variation is seen at the threshold $\Lambda$ indicating the damage initiation.

The optimization criterion for the adjusted model parameters was the best agreement between the experimental and theoretical functions: $\left\langle\varepsilon_{R D}\right\rangle_{p h}$ vs. $\Sigma_{R D}$ (Fig. 10a) and $\Sigma_{R D}$ Vs. $E_{R D}$ (Fig. 11). The determined values of the parameters describing the plastic deformation in both phases (Eq. (2)) and the damage occurring in the ferrite (Eq. (12)) are given in Table 5. When the damage process was simulated, a slightly higher work hardening (described by $\tau_{1}^{p h}$ and $\theta_{1}^{p h}$ for large deformation) was predicted for the ferrite, compared to the prediction without damage (cf. parameters for the aged UR45N steel shown in Table 4). It was observed that the damage rate characterized by $\dot{d}^{g}$ linearly depends on the rate of equivalent strain $\dot{\varepsilon}_{e q}^{g}$ (because $n^{\text {fer }}=0$ in Eq. (12)). Such a stable evolution of damage in the ferritic phase is possible due to the transfer of the load into undamaged austenite, which compensates for the softening of the ferritic phase. As presented in Fig. 10, a significant effect of the damage process is noticed for the $\Sigma_{R D}$ stresses over about $1330 \mathrm{MPa}$ (above $\Lambda$ threshold), corresponding to a large sample deformation $E_{R D}$ over ca. 0.8-1.0 (cf. $\Lambda$ threshold in Fig. 11), when for a growing number of ferrite grains the following condition is fulfilled $\varepsilon_{e q}^{g}>\varepsilon_{0}^{p h}=0.8$ (cf. Eq. (12)).

A more clear presentation of the phases behavior is shown in Fig. 12, where the arithmetical mean lattice strains $\left(<\varepsilon_{R D}>p h\right)$ calculated for each $p h$-phase are presented. It was found that, without damage, the trends of the $\left\langle\varepsilon_{R D}>p h\right.$ vs. $\Sigma_{R D}$ curves cannot be predicted, whereas a good agreement between the theoretical results and experimental data was obtained when the damage process was simulated. During damage (over $\Lambda$ threshold) a significant softening occurring in the ferritic phase causes transfer of the load from the ferrite to the undamaged austenitic grains and this effect is correctly described by the self-consistent approach. Additionally, the calculated mean phase stresses $\left\langle\sigma_{R D}>_{p h}\right.$ in the loading direction (RD) are presented in Fig. 11. It was concluded that the stress localized in the ferritic grains is higher than the stress in the austenite approximately up to applied stress $\Sigma_{R D}=1330 \mathrm{MPa}$ (i.e. below the $\Lambda$ limit, cf. Figs. 11 and 12). Subsequently, above the $\Lambda$ threshold the load transfer between phases is seen, leading to a superior stress in the austenite and saturation of the macrostress $\Sigma_{R D}$ (Fig. 11).

It should be stated, that the damage process described in the present work is studied only in the range of tensile loading for which the neutron measurements can be done (during saturation of the macrostress $\Sigma_{R D}$ subjected to the sample). This process corresponds to ductile damage at microscale level and develops gradually in the ferrite for the sample deformation range $0.8<E_{R D}<2.4$ (Fig. 11). Unfortunately, the diffraction data are not available for the range of rapid decrease of macrostress $\Sigma_{R D}$ for the strain larger than $E_{R D}=2.4$ and corresponding to fracture of the sample. The latter process was previously simulated by Panicaud et al. (2011) also assuming damage in the ferritic phase. In that work the influence of damage process on the macroscopic behavior of two-phase steel was shown comparing the model prediction obtained for different parameters of the $d^{f e r}$ function with macromechanical tensile test. However, in the work of Panicaud the diffraction data were not used and the behavior of the phases was not directly verified. The process studied in the present work corresponds to slow ductile damage detected using diffraction, while the fracture described by Panicaud et al. (2011) is a process (for $E_{R D}>2.4$ ) in which the voids and cracks may cause rapidly developing destruction of the material. Because of the different physical reasons of both processes, the determined parameters of the $d^{\text {fer }}$ function are also different.

\subsection{Adjustable parameters of the model}

In the present work our upgraded modeling procedure (proposed in the work of Panicaud et al., 2011) was applied for interpretation of the diffraction experiment performed in situ during a tensile test of duplex steel. This model describes the elastoplastic behavior of two phases, as well as the damage process occurring at grain scale. As mentioned above, the advantage of the model is a small number of adjustable parameters having physical meaning and enabling the prediction of both processes (the meaning of the parameters is given in Table 6). The other parameters introduced to the model as the input data were experimentally determined (initial grain orientations and stresses) or taken from the literature (single crystal elastic constants and families of active slip systems).

It should be highlighted, that using the present model the critical values $\tau_{0}^{p h}$ and $\varepsilon_{0}^{p h}$ can be unambiguously determined for both phases by comparing the theoretical predictions with the diffraction results. The $\tau_{0}^{p h}$ and $\varepsilon_{0}^{p h}$ parameters determine the beginning of the plastic deformation and damage process, respectively, which are clearly seen as the changes of the $\left\langle\varepsilon_{R D}\right\rangle_{p h}$ vs. $\Sigma_{R D}$ trends (cf. the thresholds $I, \Omega$ and $\Lambda$ in Fig. 12). Also, the values of $\theta_{0}^{p h}$ (hardening for small deformation), $\tau_{1}^{p h}$ and $\theta_{1}^{p h}$ (hardening for the intermediate and large deformation, below $\Lambda$ thresholds) can be determined for both phases from the slopes of $\left\langle\varepsilon_{R D}>p h\right.$ vs. $\Sigma_{R D}$ (Fig. 12) and $\Sigma_{R D}$ vs. $E_{R D}$ functions (Fig. 11) fitted to the experimental data. Finally, the values of the $n^{p h}$ and $\xi^{p h}$ parameters are adjusted for the range of deformation over $\Lambda$ threshold and they describe the stress relaxation in the ferrite, interpreted as a ductile damage process occurring in this phase. The $n^{p h}$ and $\xi^{p h}$ values influence the $\left\langle\varepsilon_{R D}>p h\right.$ vs. $\Sigma_{R D}$ evolution (Fig. 12) and the slope/nonlinearity of the macroscopic $\Sigma_{R D}$ vs. $E_{R D}$ plot (Fig. 11). 

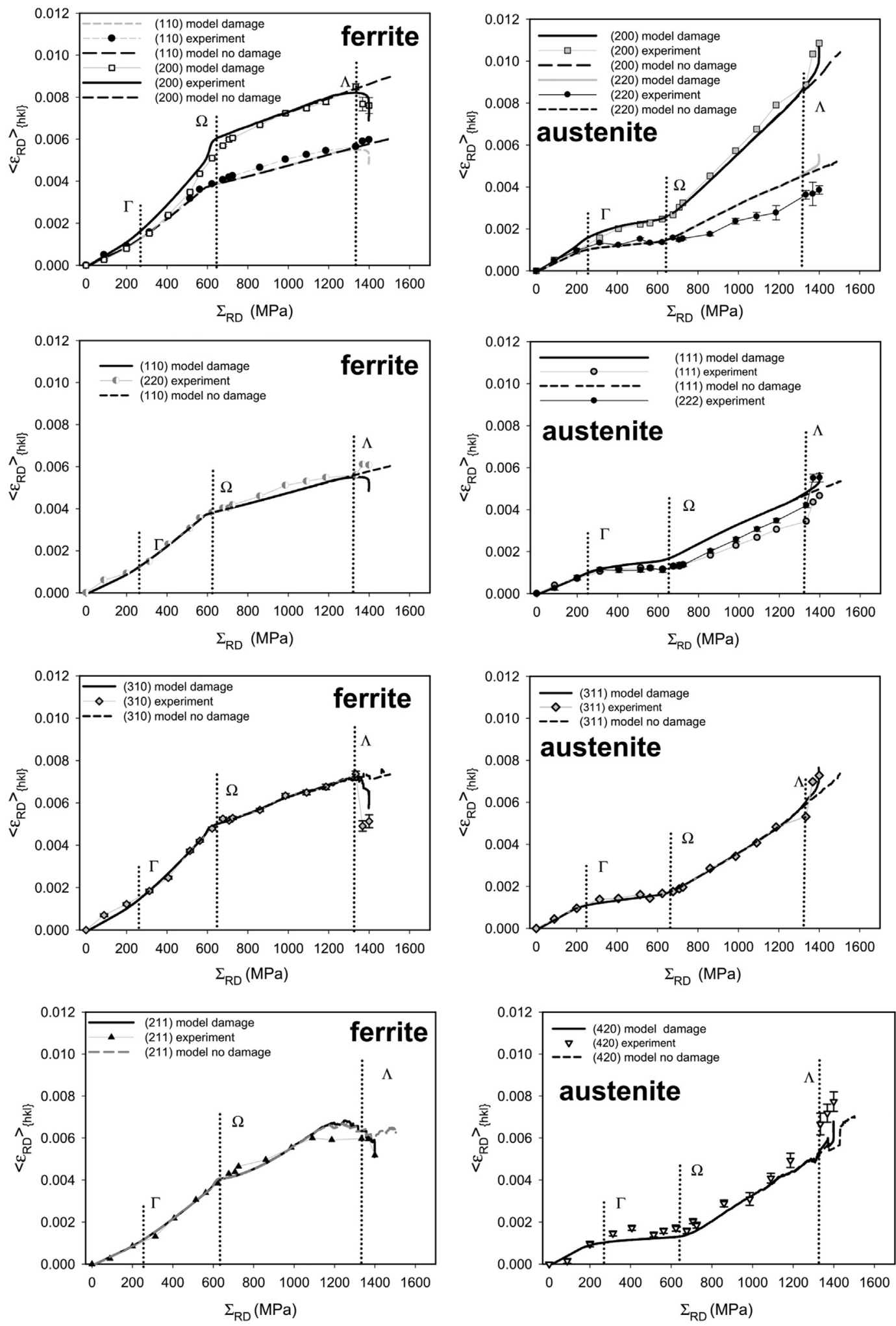

a)

Fig. 10. The lattice strains $\left\langle\varepsilon_{R D}>_{\{h k l\}}\right.$ (a) and $\left\langle\varepsilon_{T D}>_{\{h k l\}}\right.$ (b) measured vs. applied stress $\Sigma_{R D}$ in the UR45N sample and compared with the model prediction taking into account (a,b) and neglecting (a) the damage effect. The thresholds $\Gamma$ and $\Omega$ indicate the beginning of plastic deformation in austenite and ferrite, while $\Lambda$ defines the beginning of the damage process. 

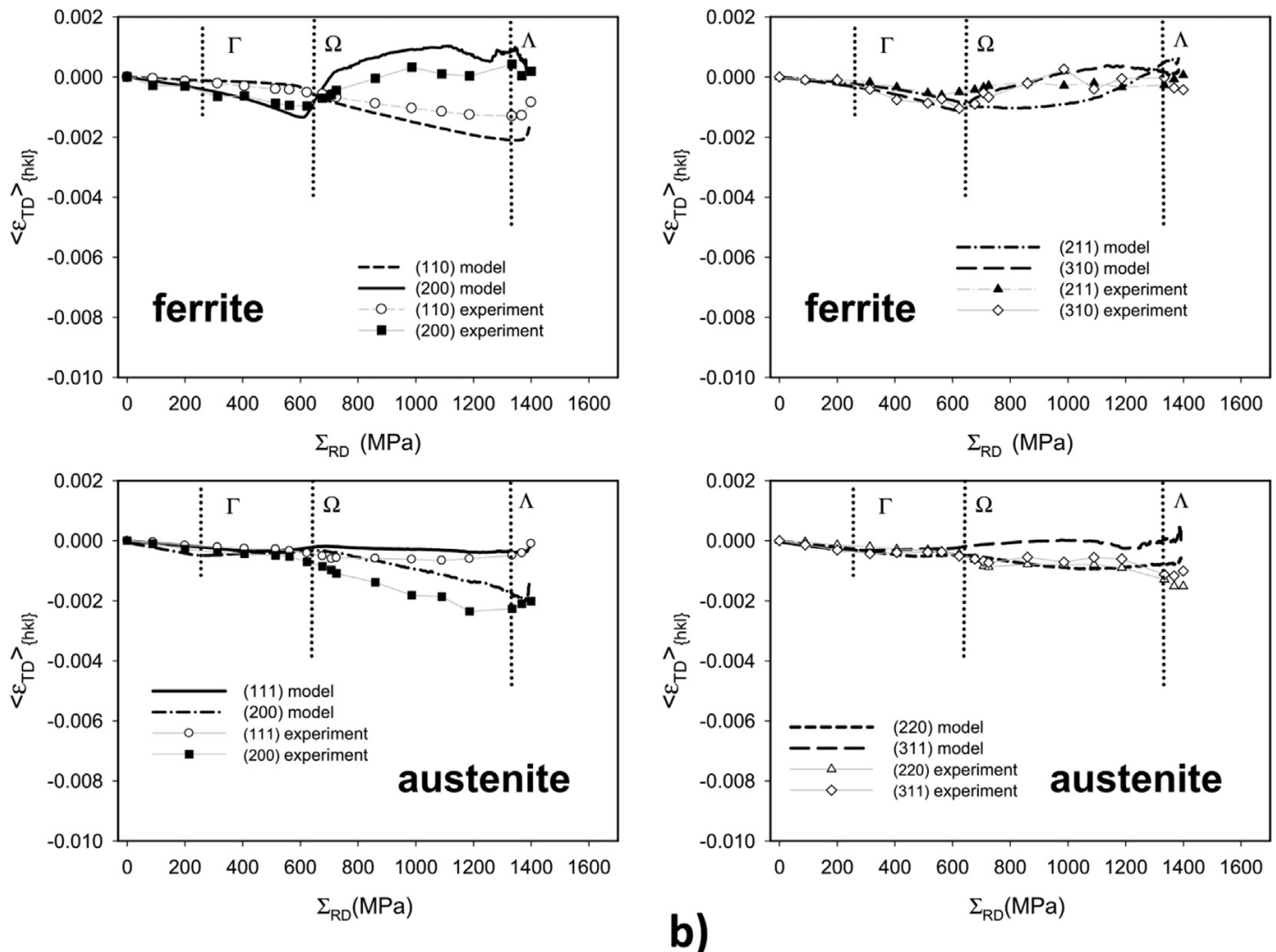

Fig. 10. (continued).

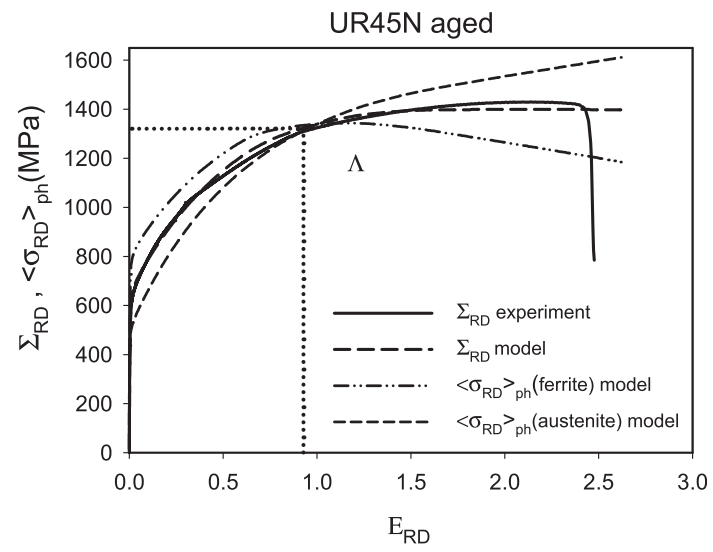

Fig. 11. The result of the tensile test conducted along RD compared with the model prediction. Additionally, the theoretical mean phase stresses $\left\langle\sigma_{R D}\right\rangle_{p h}($ along $\mathrm{RD}$ ) in function of the total sample strain $E_{R D}$ are presented. The $\Lambda$ threshold indicates the approximate beginning of the damage process.

Table 5

Parameters of plastic deformation and damage process for the aged UR45N steel (damage occurred only in the ferritic phase).

\begin{tabular}{|c|c|c|c|c|c|c|c|c|c|c|}
\hline \multicolumn{8}{|c|}{ Plastic deformation (Voce law, Eq. (2)) } & \multicolumn{3}{|c|}{ Damage (Eq. (12)) } \\
\hline \multicolumn{2}{|l|}{$\tau_{0}^{p h}(\mathrm{MPa})$} & \multicolumn{2}{|l|}{$\theta_{0}^{p h}(\mathrm{MPa})$} & \multicolumn{2}{|l|}{$\tau_{1}^{p h}(\mathrm{MPa})$} & \multicolumn{2}{|l|}{$\theta_{1}^{p h}(\mathrm{MPa})$} & \multirow{2}{*}{$\begin{array}{l}\varepsilon_{0}^{p h} \\
\text { Ferrite }\end{array}$} & \multirow{2}{*}{$\begin{array}{l}n^{p h} \\
\text { Ferrite }\end{array}$} & \multirow{2}{*}{$\frac{\xi^{p h}}{\text { Ferrite }}$} \\
\hline Austenite & Ferrite & Austenite & Ferrite & Austenite & Ferrite & Austenite & Ferrite & & & \\
\hline 140 & 350 & 225 & 110 & 280 & 150 & 6 & 5 & 0.8 & 0 & 0.2 \\
\hline
\end{tabular}



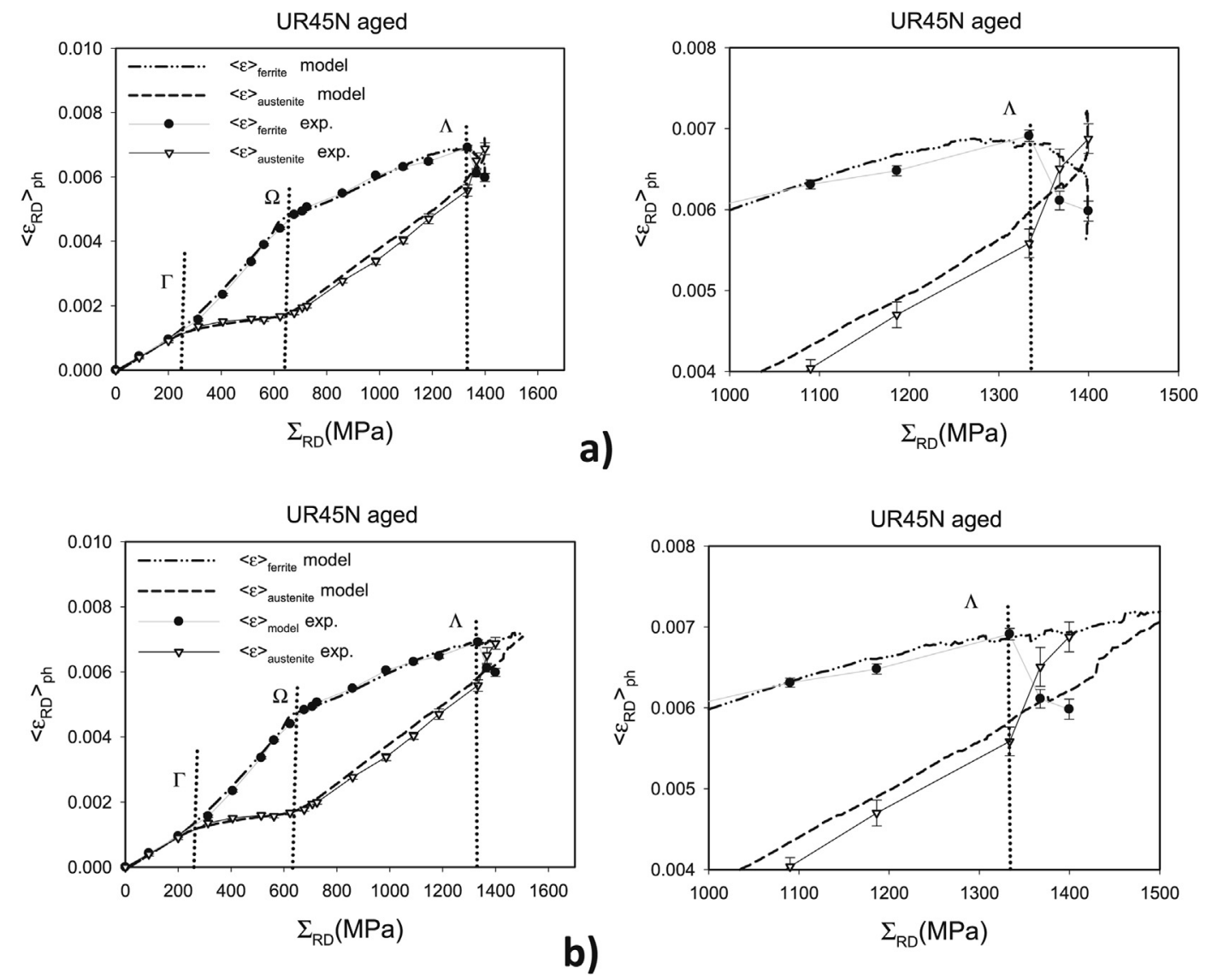

Fig. 12. The mean values of the measured elastic phase strains $\left\langle\varepsilon_{R D}>_{p h}\right.$ vs. applied stress $\Sigma_{R D}$ in the UR45N sample compared with the phase strains calculated by self-consistent model with damage (a) and without damage (b) prediction. On the right, magnification of the range close to sample fracture. The thresholds $\Gamma$ and $Q$ indicate the beginning of plasticity in austenite and ferrite, while $\Lambda$ defines the initiation of the damage process.

Table 6

Meaning of the adjustable parameters used in the self-consistent model (the independent sets of the parameters are defined for each phase $p h$ ).

\begin{tabular}{|c|c|c|c|c|}
\hline Process & & Parameter & Meaning of the parameter & Effects of the parameter on the results \\
\hline \multirow{4}{*}{$\begin{array}{l}\text { Plastic } \\
\text { deformation } \\
\text { (Eq. (2)) }\end{array}$} & $\begin{array}{l}\text { Small } \\
\text { deformation }\end{array}$ & $\tau_{0}^{p h}$ & Initial value of CRSS & $\begin{array}{l}\text { Determines the yield stress for the ph-phase (shifts the } T \text { and } \Omega \\
\text { thresholds seen on the }\left\langle\varepsilon_{R D}>_{p h} \text { vs. } \Sigma_{R D} \text { curves in Fig. 12). }\right.\end{array}$ \\
\hline & & $\theta_{0}^{p h}$ & Initial hardening of the slip system & \multirow[t]{3}{*}{$\begin{array}{l}\text { Determines the slopes of the }\left\langle\varepsilon_{R D}>p h \text { vs. } \Sigma_{R D} \text { curves (range above } \Omega \text { and }\right. \\
\text { below } \Lambda \text { in Fig. 12) and the slope/nonlinearity of the macroscopic } \Sigma_{R D} \text { vs } \\
E_{R D} \text { plot (Fig. 11). }\end{array}$} \\
\hline & $\begin{array}{l}\text { Large } \\
\text { deformation }\end{array}$ & $\overline{\tau_{1}^{p h}}$ & $\begin{array}{l}\text { Back-extrapolated CRSS (by a tangent } \\
\text { line) }\end{array}$ & \\
\hline & & $\theta_{1}^{p h}$ & $\begin{array}{l}\text { Final hardening of the slip system (large } \\
\text { deformation) }\end{array}$ & \\
\hline \multirow[t]{2}{*}{$\begin{array}{l}\text { Damage } \\
\text { (Eq. (12)) }\end{array}$} & $\begin{array}{l}\text { Damage } \\
\text { initiation }\end{array}$ & $\varepsilon_{0}^{p h}$ & $\begin{array}{l}\text { Critical value of equivalent total strain } \\
\text { of a given grain, for which damage is } \\
\text { initiated }\end{array}$ & $\begin{array}{l}\text { Determines the initiation of damage/softening indicated by threshold } \Lambda \text {, } \\
\text { seen on the }\left\langle\varepsilon_{R D}\right\rangle_{\text {ph }} \text { vs. } \Sigma_{R D} \text { curves (Fig. 12). }\end{array}$ \\
\hline & $\begin{array}{l}\text { Damage } \\
\text { evolution }\end{array}$ & $n^{p h}, \xi^{p h}$ & $\begin{array}{l}\text { Parameters describing evolution of } \\
\text { damage occurring at the grain scale }\end{array}$ & $\begin{array}{l}\text { Determines the }\left\langle\varepsilon_{R D}>p h \text { vs. } \Sigma_{R D} \text { evolution (Fig. 12) above } \Lambda \text { thresholds }\right. \\
\text { and influences the slope/nonlinearity of the macroscopic } \Sigma_{R D} \text { vs. } E_{R D} \text { plot } \\
\text { (Fig. 11). }\end{array}$ \\
\hline
\end{tabular}

\section{Conclusions}

As demonstrated in this work, the important advantage of the diffraction experiment is the possibility to separate measurements of the mechanical properties for each phase in multiphase polycrystalline materials, with duplex steel as an example. The lattice strains measured in situ by neutron or synchrotron diffraction during sample loading were compared with the prediction of the self-consistent model, and the resulting elastoplastic deformation as well as the damage process were studied for each phase. Different critical resolved shear stresses in phases were identified for samples having different 
compositions and/or subjected to different heat treatments. It was demonstrated that similar macro-mechanical behavior of the samples can result from different micro-mechanical properties at a grain scale. It was also observed that the initial residual stresses between phases significantly change the behavior of these phases in the studied materials.

The diffraction data obtained for a sample subjected to large deformation were analyzed using the self-consistent approach in which ductile damage in a given phase was considered in calculations. It was concluded that a significant sample softening of the aged UR45N steel was caused by the damage process initiated in the ferrite and a load transfer from the damaged ferritic grains to the undamaged austenitic grains occurred. The advantage of the presented method is that the elastoplastic deformation and micro-damage process can be correctly described by a small number of adjustable parameters having a physical meaning.

\section{Acknowledgments}

The work was supported partly by the NCN - Polish National Center for Science, grants: No. UMO - 2011/03/N/ST8/04058 and DEC - 2013/11/B/ST3/03787; and partly by the MNiSW - Polish Ministry of Science and Higher Education.

Measurements at the ISIS neutron source were founded by a beamtime allocation (RB820145) from the STFC. We also acknowledge the European Synchrotron Radiation Facility (ESRF) for the provision of synchrotron radiation facilities in the framework of the MA 1611.

\section{References}

Abu Al-Rub, R.K., Voyiadjis, G.Z., 2003. On the coupling of anisotropic damage and plasticity models for ductile materials. Int. J. Solids Struct. 40, $2611-2643$.

Alvarez-Armas, I., Krupp, U., Balbi, M., Hereñú, S., Marinelli, M.C., Knobbe, H., 2012. Growth of short cracks during low and high cycle fatigue in a duplex stainless steel. Int. J. Fatigue 41, 95-100.

Baczmański, A., Braham, C., 2004. Elastoplastic properties of duplex steel determined using neutron diffraction and self-consistent model. Acta Mater. 52, $1133-1142$.

Baczmański, A., Le Joncour, L., Panicaud, B., Francois, M., Braham, C., Paradowska, A.M., Wroński, S., Amara, S., Chiron, R., 2011. Neutron TOF diffraction used to study aged duplex stainless steel at small and large deformation until sample fracture. J. Appl. Cryst. 44, 966-982.

Balieu, R., Kringos, N., 2015. A new thermodynamical framework for finite strain multiplicative elastoplasticity coupled to anisotropic damage. Int. J. Plast. 70, 126-150.

Balbi, M., Avalos, M., Bartali, E., Alvarez-Armas, I., 2009. Microcrack growth and fatigue behavior of a duplex stainless steel. Int. J. Fatigue 31, $2006-2013$.

Basirat, M., Shrestha, T., Potirniche, G.P., Charit, I., Rink, K., 2012. A study of the creep behavior of modified 9Cr-1Mo steel using continuum-damage modeling. Int. J. Plast. 37, 95-107.

Bettaieb, M.B., Lemoine, X., Bouaziz, O., Habraken, A.M., Duchêne, L., 2011. Numerical modeling of damage evolution of DP-steels on the basis of X-ray tomography measurements. Mech. Mat. 43, 139-156.

Bonnet, S., Bourgoin, J., Champredonde, J., Guttmann, D., Guttmann, M., 1990. Relationship between evolution of mechanical properties of various cast duplex stainless steels and metallurgical and aging parameters. Mater. Sci. Tech. 6, 221-229.

Boudifa, M., Saanouni, K., Chaboche, J.-L., 2009. A micromechanical model for inelastic ductile damage prediction in polycrystalline metals for metal forming. Int. J. Mech. Sci. 51, 453-464.

Brünig, M., 2003. An anisotropic ductile damage model based on irreversible thermodynamics. Int. J. Plast. 19, 1679-1713.

Brünig, M., Gerke, S., Hagenbrock, V., 2015. Stress-state dependence of damage strain rate tensors caused by growth and coalescence of microdefects. Int. J. Plast. 63, 49-63.

Bugat, S., Besson, J., Gourgues, A.F., N'Guyen, F., Pineau, A., 2001. Microstructure and damage initiation in duplex stainless steel. Mater. Sci. Eng. A 317, $32-36$.

Cailletaud, G., Pilvin, P., 1994. Utilisation de modèles polycristallins pour le calcul par eléments finis. Rev. Eur. Des. Éléments finis 3, 515-541.

Chaboche, J.-L., Kruch, S., Maire, J.-F., Pottier, T., 2001. Towards a micromechanics based inelastic and damage modelling of composites. Int. J. Plast. 17, 411-439.

Clausen, B., Lorentzen, T., Bourke, M.A.M., Daymond, M.R., 1999. Lattice strain evolution during uniaxial tensile loading of stainless steel. Mater. Sci. Eng. A $259,17-24$.

Dakhlaoui, R., Baczmański, A., Braham, C., Wroński, S., Wierzbanowski, K., Oliver, E.C., 2006. Effect of residual stresses on individual phase mechanical properties of austeno- ferritic duplex stainless steel. Acta Mater. 54, 5027-5039.

Dakhlaoui, R., Braham, C., Baczmański, A., 2007. Mechanical properties of phases in austeno-ferritic duplex stainless steel - surface stresses studied by x-ray diffraction. Mater. Sci. Eng. A 444, 6-17.

Daymond, M.R., Priesmeyer, H.G., 2002. Elastoplastic deformation of ferritic steel and cementite studied by neutron diffraction and self-consistent modelling. Acta Mater. 50, 1613-1623.

Dormieux, L., Kondo, D., 2015. Exact solutions for an elastic damageable hollow sphere subjected to isotropic mechanical loadings. Int. J. Mech. Sci. 90, $25-32$.

Ekh, M., Lillbacka, R., Runesson, K., 2004. A model framework for anisotropic damage coupled to crystal (visco) plasticity. Int. J. Plast. 20, 2143-2159.

Egner, H., Skoczeń, B., 2010. Ductile damage development in two-phase materials applied at cryogenic temperatures. Int. J. Plast. 26, $488-506$.

El Bartali, A., Aubin, V., Degallaix, V., 2008. Fatigue damage analysis in a duplex stainless steel by digital image correlation technique. Fatigue Fract. Engng. Mater. Struct. 31, 137-151.

El Bartali, A., Evrard, P., Aubin, V., Herenú, S., Alvarez-Armas, I., Armas, A.F., Degallaix-Moreuil, S., 2010. Strain heterogeneities between phases in a duplex stainless steel. Comparison between measures and simulation. Procedia Eng. 2, 2229-2237.

Eshelby, J.D., 1957. The determination of the elastic field of an ellipsoidal inclusion and related problems. Proc. R. Soc. Lond. A 241, 376-396.

Francis, E.M., Grant, B.M.B., Quinta da Fonseca, J., Phillips, P.J., Mills, M.J., Daymond, M.R., Preuss, M., 2014. High-temperature deformation mechanisms in a polycrystalline nickel-base superalloy studied by neutron diffraction and electron microscopy. Acta Mater. 74, 18-29.

Franz, G., Abed-Meraim, F., Berveiller, M., 2013. Strain localization analysis for single crystals and polycrystals : towards microstructure-ductility linkage. Int. J. Plast. $48,1-33$.

Franz, G., Abed-Meraim, F., Berveiller, M., 2014. Effect of microstructural and morphological parameters on the formability of BCC metal sheets. Steel Res. Int. 85, 980-987.

Fréour, S., Gloaguen, D., François, M., Guillén, R., 2003. Modelling and simulation of multiphase effects on X-Ray Elasticity Constants. Phys. Status Solidi (b) 239, 297-309.

Gloaguen, D., Oum, G., Legrand, V., Fajoui, J., Branchu, S., 2013. Experimental and theoretical studies of intergranular strain in an alpha titanium alloy during plastic deformation. Acta Mater. 61, 5779-5790. 
Gonzàlez, C., LLorca, J., 2000. A self-consistent approach to the elastoplastic behaviour of two-phase materials including damage. J. Mech. Phys. Solids 48, 675-692.

Gonzàlez, C., Segurado, J., LLorca, J., 2004. Numerical simulation of elasto-plastic deformation of composites: evolution of stress microfields and implications for homogenization models. J. Mech. Phys. Solids 52, 1573-1593.

Hammersley, A.P., Svensson, S.O., Hanfland, M., Fitch, S.O., Häusermann, D., 1996. Two-dimensional detector software: from real detector to idealised image or two-theta scan. High Press. Res. 14, 235-248.

Haušild, P., Berdina, C., Bomparda, P., Verdièrec, N., 2001. Ductile fracture of duplex stainless steel with casting defects. Int. J. Pres. Vessel. Pip. 78, 607-616.

Inal, K., Gergaud, P., Francois, M., Lebrun, J.-L., 1999. X-ray diffraction methodologies of macro and pseudo- macro stress analysis in a textured duplex stainless steel. Scand. J. Metall. 28, 139-150.

Istomin, K., Dönges, B., Schell, N., Christ, H.-J., Pietsch, U., 2014. Analysis of VHCF damage in a duplex stainless steel using hard X-ray diffraction techniques. Int. J. Fatigue 66, 177-182.

Jia, N., Lin Peng, R., Wang, Y.D., Johansson, S., Liaw, P.K., 2008. Micromechanical behavior and texture evolution of duplex stainless steel studied by neutron diffraction and self- consistent modeling. Acta Mater 56, 782-793.

Jia, N., Cong, Z.H., Sun, X., Cheng, S., Nie, Z.H., Ren, Y., Liaw, P.K., Wang, Y.D., 2009. An in situ high energy X-ray diffraction study of micromechanical behavior of multiple phases in advanced high-strength steels. Acta Mater. 57, 3965-3977.

Kallend, J.S., Kocks, U.F., Rollet, A.D., Wenk, H.R., 1990. Operational Texture Analysis. Rap. LA-UR-90-2852. CMS, Los Alamos National Laboratory, USA.

Kruch, S., Chaboche, J.-L., 2011. Multi-scale analysis in elasto-viscoplasticity coupled with damage. Int. J. Plast. 27, 2026-2039.

Krupp, U., Giertler, A., Söker, M., Fub, H., Dönges, B., Christ, H.-J., Hüsecken, A., Pietsch, U., Fritzen, C.-P., Ludwig, W., 2015. The behavior of short fatigue cracks during Very High Cycle (VHCF) Fatigue of duplex stainless steel. Eng. Fract. Mech. 145, 197-209.

Lecarme, L., Tekoglu, C., Pardoen, T., 2011. Void growth and coalescence in ductile solids with stage III and stage IV strain hardening. Int. J. Plast. 27, $1203-1223$.

Lagneborg, R., 1967. Deformation on in an Iron-30\% chromium Alloy aged at $475^{\circ}$ C. Acta Metall. 15, 1737-1745.

Le Joncour, L., Panicaud, B., Baczmański, A., Francois, M., Braham, C., Paradowska, A., Wroński, S., Chiron, R., 2010. Damage in duplex steels studied at mesoscopic and macroscopic scales. Mech. Mater 42, 1048-1063.

Lemaitre, J., Chaboche, J.-L., 1978. Aspect phenomenologique de la rupture par endommagement. J. de Mecanique Appliquee (Paris) 2, 317-365.

Li, H., Fu, M.W., Lu, J., Yang, H., 2011. Ductile fracture: experiments and computations. Int. J. Plast. 27, 147-180.

Lipinski, P., Berveiller, M., 1989. Elastoplasticity of micro- inhomogeneous metals at large strains. Int. J. Plast. 5, $149-172$.

Maire, E., Bordreuil, C., Babouta, L., Boyer, J.-C., 2005. Damage initiation and growth in metals. Comparison between modelling and tomography experiments. J. Mech. Phys. Solids 53, 2411-2434.

Malcher, L., Andrade Pires, F.M., César De Sá, J.M.A., 2014. An extended GTN model for ductile fracture under high and low stress triaxiality. Int. J. Plast. 54, $193-228$.

Marotti De Sciarra, F., 2012. Hardening plasticity with nonlocal strain damage. Int. J. Plast. 34, 114-138.

M'Cirdi, L., Lebrun, J.L., Inal, K., 2001. Experimental approach of a crystallographic cleavage criterion in a cast aged duplex stainless steel. Acta Mater. 29, 3879-3887.

Merkel, S., 2011. Multifit/Polydefix Polycrystal Deformation Using X-rays available at: https://code.google.com/p/multifit-polydefix.

Michel, J.-C., Suquet, P., 2003. Nonuniform transformation field analysis. Int. J. Solids Struct. 40, 6937-6955.

Mohr, C.O., 1900. Welche Umstände bedingen die Elastizitätsgrenze und den Bruch eines Materials? Z. Ver. Dtsch. Ing. Band. 44, 1524-1530.

Mori, T., Tanaka, K., 1973. Average stress in matrix and average elastic energy of materials with misfitting inclusions. Acta Metall. $21,571-574$.

Murakami, S., 2012. Continuum Damage Mechanics: a Continuum Mechanics Approach to the Analysis of Damage and Fracture. Springer-Verlag.

Nguyen, G.D., Korsunsky, A.M., Belnoue, J.P.-H., 2015. A nonlocal coupled damage-plasticity model for the analysis of ductile failure. Int. J. Plast. 64, 56-75.

Neil, C.J., Wollmershauser, J.A., Clausen, B., Tomé, C.N., Agnew, S.R., 2010. Modeling lattice strain evolution at finite strains. Model verification for copper and stainless steel using in-situ diffraction measurement. Int. J. Plast. 26, 1772-1791.

Panicaud, B., Saanouni, K., Baczmański, A., François, M., Cauvin, L., Le Joncour, L., 2011. Theoretical modelling of ductile damage in duplex stainless steels comparison between two micro-mechanical elastoplastic approaches. Comp. Mat. Sci. 50, 1908-1916.

Park, C.J., Kwon, H.S., 2002. Effects of aging at $475^{\circ} \mathrm{C}$ on corrosion properties of tungsten-containing duplex stainless steels. Corros. Sci. 44, $2817-2830$.

Pijaudier-Cabot, G., Bažant, Z.P., 1987. Nonlocal damage theory. ASCE J. Eng. Mech. 113, 1512-1533.

Prahl, J., Machová, A., Spielmannová, A., Karlík, M., Landa, M., Haušild, P., Lejček, P., 2010. Ductile-brittle behavior at the (110)[001] crack in bcc iron crystals loaded in model. Eng. Fract. Mech. 77, 184-192.

Ran, J.Q., Fu, M.W., 2014. A hybrid model for analysis of ductile fracture in micro-scaled plastic deformation of multiphase alloys. Int. J. Plast. 61, 1-16.

Rousselier, G., Luo, M., 2014. A fully coupled void damage and Mohr-Coulomb based ductile fracture model in the framework of a Reduced Texture Methodology. Int. J. Plast. 55, 1-24.

Rousselier, G., Quilici, S., 2015. Combining porous plasticity with Coulomb and Portevin-Le-Chatelier models for ductile fracture analyses. Int. J. Plast. 69, $118-133$.

Saanouni, K., Abdul-Latif, A., 1996. Micromechanical modeling of low-cycle fatigue under complex loadings .1. Theoretical formulation. Int. J. Plast. 12, $1111-1121$.

Santisteban, J., James, J., Daymond, M., Edwards, L., 2006. ENGIN-X: a third-generation neutron strain scanner. J. Appl. Cryst. $39,812-825$.

Shojaei, A., Li, G., 2013. Viscoplasticity analysis of semicrystalline polymers: a multiscale approach within micromechanics framework. Int. J. Plast. 42, $31-49$.

Strubbia, R., Hereñú, S., Krupp, U., Alvarez-Armas, I., 2014. Short fatigue cracks nucleation and growth in lean duplex stainless steel LDX2101. Mat. Sci. Eng. A615, 169-174.

Tekoğlu, C., Pardoen, T., 2010. A micromechanics based damage model for composite materials. Int. J. Plast. 26, 549-569.

Tome, C., Canova, G.R., Kocks, U.F., Christodoulou, N., Jonas, J.J., 1984. The relation between macroscopic and microscopic strain hardening in f.c.c. polycrystals. Acta Metall. 32, 1637-1653.

Turner, P.A., Tomé, C.N., 1994. A study of residual stresses in Zircaloy-2 with rod texture. Acta Metall. Mater 42, 4143-4153.

Vignjevic, R., Djordjevic, N., Panov, V., 2012. Modelling of dynamic behaviour of orthotropic metals including damage and failure. Int. J. Plast. 38 , 47-85.

Wroński, S., Baczmański, A., Dakhlaoui, R., Braham, C., Wierzbanowski, K., Oliver, E.C., 2007. Determination of stress field in textured duplex steel using TOF neutron diffraction method. Acta Mater. 55, 6219-6233. 